\title{
lonic liquid-plasticised composites of chitosan and hybrid 1D and 2D nanofillers
}

Pei Chen ${ }^{1,2}$, Fengwei Xie $2^{2^{*}}$, Fengzai Tang ${ }^{3}$ and Tony McNally ${ }^{2^{*}}$ (])

\begin{abstract}
The focus of this research was to study the effect of combining nanofillers with different geometry and surface chemistry on the structure and properties of biopolymers as an alternative to traditional plastics. How the inclusion of 2D graphene oxide (GO) or reduced $\mathrm{GO}(\mathrm{rGO})$ combined with 1D sepiolite (SPT) or cellulose nanocrystals (CNCs) affect the structure and properties of chitosan and chitosan/carboxymethyl cellulose (CMC) materials was investigated. A 3D interconnected microstructure formed, composed of GO and SPT due to the strong interactions between these hydrophilic nanofillers. The chitosan/CMC/GO/SPT composite had the highest tensile strength (77.5 $\pm 1.2 \mathrm{MPa})$ and Young's modulus (1925.9 $\pm 120.7 \mathrm{MPa}$ ). For the un-plasticised matrices, hydrophobic $\mathrm{rGO}$ nanosheets generally hindered the interaction of SPT or CNCs with the polysaccharides (chitosan and CMC) and consequently, composite properties were mainly determined by the $\mathrm{rGO}$. However, for the chitosan matrix plasticised by 1-ethyl-3-methylimidazolium acetate ([ $\mathrm{C}_{2}$ mim] $\left.[\mathrm{OAc}]\right), \mathrm{rGO}+\mathrm{CNCS}$ or $\mathrm{rGO}+\mathrm{SPT}$ disrupted polymer chain interactions more effectively than the nanofillers when added alone and resulted in the chitosan being more plasticised, as shown by increased chain mobility, ductility, and surface hydrophilicity. For the $\left[\mathrm{C}_{2}\right.$ mim] $[\mathrm{OAc}]$-plasticised chitosan/CMC matrix, the advantages of including hybrid fillers, rGO + CNCs or rGO + SPT, were also obtained, resulting in higher thermal stability and surface hydrophobicity.
\end{abstract}

Keywords: Biopolymer nanocomposites, Polysaccharide plasticisation, Graphene oxide, Sepiolite, Cellulose nanocrystals, lonic liquid

\footnotetext{
*Correspondence: d.xie.2@warwick.ac.uk; fwhsieh@gmail.com;

t.mcnally@warwick.ac.uk

${ }^{2}$ International Institute for Nanocomposites Manufacturing (IINM), WMG,

University of Warwick, Coventry CV4 7AL, UK

Full list of author information is available at the end of the article
}

\section{Springer Open}

(c) The Author(s) 2021. Open Access This article is licensed under a Creative Commons Attribution 4.0 International License, which permits use, sharing, adaptation, distribution and reproduction in any medium or format, as long as you give appropriate credit to the original author(s) and the source, provide a link to the Creative Commons licence, and indicate if changes were made. The images or other third party material in this article are included in the article's Creative Commons licence, unless indicated otherwise in a credit line to the material. If material is not included in the article's Creative Commons licence and your intended use is not permitted by statutory regulation or exceeds the permitted use, you will need to obtain permission directly from the copyright holder. To view a copy of this licence, visit http://creativecommons.org/licenses/by/4.0/. 


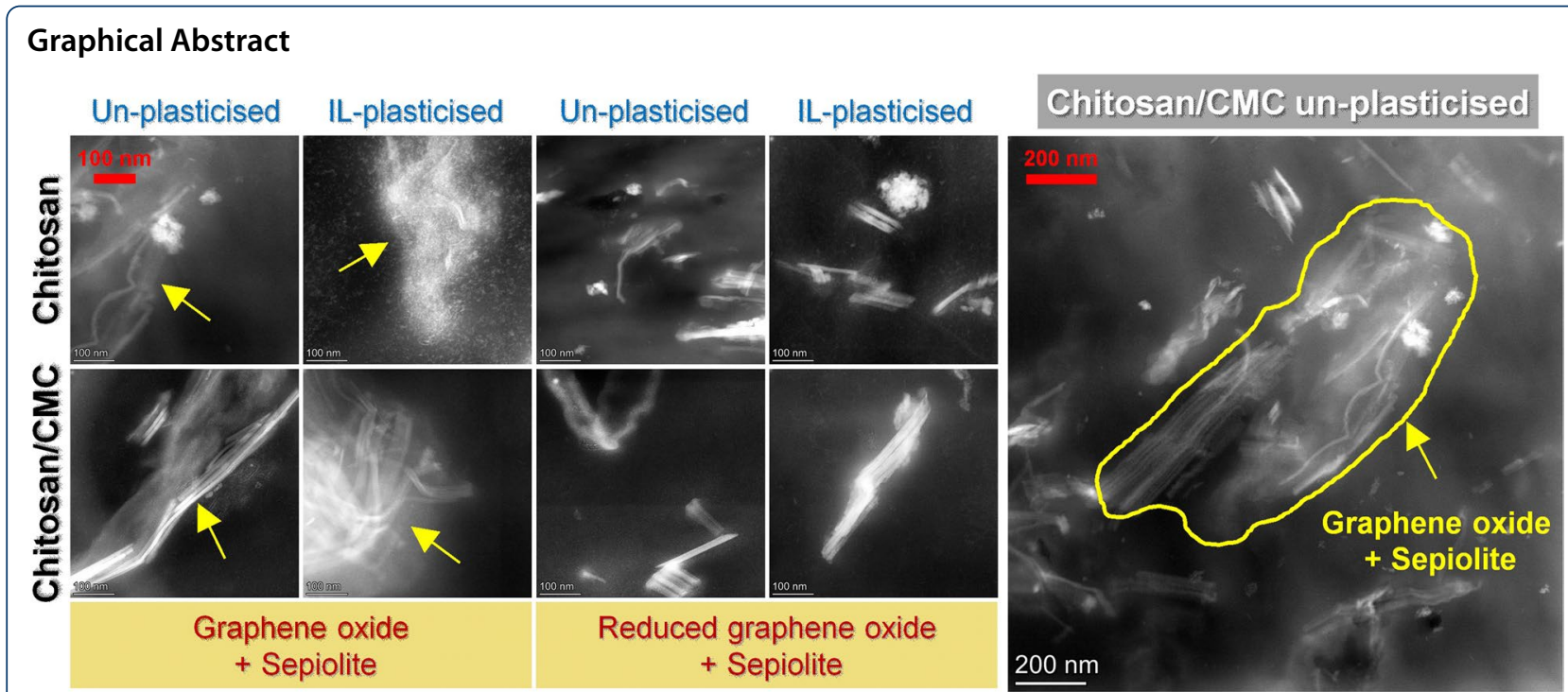

\section{Introduction}

Chitosan is renewable, biodegradable, biocompatible, non-toxic, biologically tolerant, and hydrolysable by lysozymes and has excellent film-forming, hydration, wound healing, antifungal and antimicrobial properties [1]. Due to these appealing and useful properties, chitosan has been extensively studied for application in biomedical treatment, pharmaceutics, food, cosmetics, biotechnology, water treatment, agriculture, textiles, and papermaking [1-4].

Chitosan due to its abundant hydroxyl and amino functional groups can be chemically modified as a route to new or improved properties [5]. Nonetheless, a more convenient and cost-effective method to modify chitosan could be by blending it with other polymers, especially biopolymers. Cellulose is another important polysaccharide widely available in plants and constitutes the most abundant renewable polymer resource [6]. Blends of chitosan with cellulose have been widely studied, displaying antibacterial activity, metal ion absorbency, odour treatment characteristics, increased water or moisture absorption capacity, enhanced mechanical properties, good antistatic behaviour, high porosity, and self-healing effects [7]. Generally, such materials are made through dissolving chitosan and cellulose in a solvent followed by regeneration [7], which can be time- and chemically intensive. Moreover, the properties of chitosan/cellulose blends are dependent on the way of biopolymer chain interactions. For example, it was found that the mechanical and dynamic mechanical thermal properties of chitosan/cellulose films prepared by dissolving the polysaccharides in trifluoroacetic acid and casting were dominated by cellulose, which was supposed to be due to the strong intra-molecular and intra-strand hydrogen bonding remaining within cellulose [8]. However, no phase separation was found for chitosan/cellulose materials obtained by regeneration from the ionic liquid (IL) 1-butyl-3-methylimidazolium acetate $\left(\left[\mathrm{C}_{4} \mathrm{mim}\right][\mathrm{OAc}]\right)$ as a solvent [9].

Carboxymethyl cellulose (CMC) is chemically derived from cellulose, with some hydroxyl groups replaced by carboxymethyl groups $\left(-\mathrm{CH}_{2}-\mathrm{COOH}\right)$, which makes it water-soluble. More importantly, CMC is negatively charged and can ionically complexed with the chitosan polycation at appropriate $\mathrm{pH}[10]$. Chitosan/CMC blends have demonstrated enhanced properties for various applications such as in functional food packaging [11-13] and tissue engineering [14-17]. Excellent oil/water-barrier properties were shown by a chitosan/CMC coating [18]. The $\mathrm{pH}$-controlled swelling behaviour $[19,20]$ and enhanced hydrolytic stability [21] of chitosan/CMC composites have been demonstrated. Moreover, chitosan/ CMC-based smart materials for $\mathrm{pH}$ - or electrically sensitive actuators have been developed [22, 23].

Creating nanocomposites is another important strategy to enhance the properties of polysaccharide materials [24]. Some of the most important nanofillers include nanoclays (e.g. sepiolite, or SPT), graphene/graphene oxide (GO), and polysaccharide nanocrystals (e.g. cellulose nanocrystals, or CNCs). Graphene is a 2D nanomaterial having extraordinary mechanical properties, thermal conductivity, and electronic transport properties [25]. It has been demonstrated that graphenic nanomaterials have antimicrobial activity [26-29], which may complement the antimicrobial properties of chitosan. GO has oxygen-containing hydrophilic groups (e.g. carboxylic 
acid and phenolic hydroxyl groups) on the platelets and the ionisation of these groups in water makes GO negatively charged [30]. Nanoclays such as SPT are hydrophilic and negatively charged in their natural forms due to isomorphic substitutions occurring in the inter-gallery spacing between the clay platelets [31, 32]. CNCs prepared by acid hydrolysis contain negative sulphate halfesters [33, 34] and are also hydrophilic. Thus, all these nanofillers have the potential to strongly interact with chitosan as a polycation. Chitosan-based nanocomposites have been studied to some extent including our recent reports $[35,36]$ showing the different enhancement effects of GO, CNCs, and SPT when used alone. However, the effect of combined nanofillers with varied geometry and surface chemistry on the structure and properties of polysaccharide-based materials has barely been explored, which forms the intention of this research. A previous study [37] indicated that GO and CNCs, when added together into polyvinyl alcohol (PVA), provided a synergistic effect on the mechanical and thermal properties of the material as CNCs may assist with the de-agglomeration of $\mathrm{GO}$ platelets, leading to a 3D interconnected microstructure of $\mathrm{CNCs} / \mathrm{GO}$. This phenomenon is worth further examination with polysaccharide matrices.

Thus in this work, we developed polysaccharide-based nanocomposites filled with hydrophilic GO or hydrophobic reduced GO (rGO) combined with hydrophilic SPT or CNCs. The polysaccharide matrices studied were chitosan alone and that blended with $\mathrm{CMC}$ and were either un-plasticised or plasticised with an IL, 1-ethyl3-methylimidazolium acetate $\left(\left[\mathrm{C}_{2} \mathrm{mim}\right][\mathrm{OAc}]\right)$. This current study was conducted based on the hypothesis that, for polysaccharide nanocomposites with combined nanofillers, the effects of the nanofillers could be either counteracting or synergistic, depending on the nanofiller chemistry (hydrophilicity/hydrophobicity), polysaccharide matrix, and plasticisation. Conceivably, in such systems, there would be multiple interactions among material components that influence the matrix structure and properties, a topic which has not been systematically studied before. We found novel ways of interacting and novel structures formed when combined nanofillers were included, which could add important, new knowledge to the area of biopolymer-based composites.

\section{Experimental \\ Materials}

Chitosan was purchased from Shanghai Ryon Biological Technology Co., Ltd (China) and CMC as a sodium salt from Shanghai Macklin Biochemical Co., Ltd (China). This chitosan has a degree of deacetylation (DD) of $>90 \%$, a viscosity of $\sim 100 \mathrm{mPa} \cdot \mathrm{s}$ (i.e. $1 \%$ solution in $1 \%$ acetic acid at $25{ }^{\circ} \mathrm{C}$ ), and an $M_{\mathrm{w}}$ of $\sim 150 \mathrm{k} \mathrm{g} \cdot \mathrm{mol}^{-1}$, and was characterised before [38]. The CMC has a degree of substitution (DS) of 0.7 , a viscosity of 50-100 mPa.s (Brookfield, $2 \%$ solution, at $25{ }^{\circ} \mathrm{C}$ ), and an $M_{\mathrm{w}}$ of $90 \mathrm{k} \mathrm{g} \cdot \mathrm{mol}^{-1}$, of which the characteristics were also reported previously [21]. $\mathrm{NaBr}$ (pure) and formic acid (98\% w/w AR)

Table 1 Sample codes and compositions (presented as portions by weight)

\begin{tabular}{|c|c|c|c|c|}
\hline Sample code & Biopolymer matrix & {$\left[\mathrm{C}_{2} \mathrm{mim}\right][\mathrm{OAc}]$} & Nanofillers & $\begin{array}{l}2 \mathrm{M} \text { Formic } \\
\text { acid } \\
\text { solution }\end{array}$ \\
\hline A/GOS-F & 100 Chitosan & - & $0.375 \mathrm{GO}+0.375 \mathrm{SPT}$ & 261 \\
\hline A/GOC-F & 100 Chitosan & - & $0.375 \mathrm{GO}+0.375 \mathrm{CNCs}$ & 261 \\
\hline $\mathrm{A} / \mathrm{rGOS}-\mathrm{F}$ & 100 Chitosan & - & $0.375 \mathrm{rGO}+0.375 \mathrm{SPT}$ & 261 \\
\hline $\mathrm{A} / \mathrm{rGOC}-\mathrm{F}$ & 100 Chitosan & - & $0.375 \mathrm{rGO}+0.375 \mathrm{CNCs}$ & 261 \\
\hline AE2/GOS-F & 100 Chitosan & 20 & $0.375 \mathrm{GO}+0.375 \mathrm{SPT}$ & 261 \\
\hline AE2/GOC-F & 100 Chitosan & 20 & $0.375 \mathrm{GO}+0.375 \mathrm{CNCs}$ & 261 \\
\hline AE2/rGOS-F & 100 Chitosan & 20 & $0.375 \mathrm{rGO}+0.375 \mathrm{SPT}$ & 261 \\
\hline$A E 2 / r G O C-F$ & 100 Chitosan & 20 & $0.375 \mathrm{rGO}+0.375 \mathrm{CNCs}$ & 261 \\
\hline B/GOS-F & 100 Chitosan & - & $0.375 \mathrm{GO}+0.375 \mathrm{SPT}$ & 261 \\
\hline B/GOC-F & 100 Chitosan & - & $0.375 \mathrm{GO}+0.375 \mathrm{CNCs}$ & 261 \\
\hline $\mathrm{B} / \mathrm{rGOS}-\mathrm{F}$ & 50 Chitosan + 50 CMC & - & $0.375 \mathrm{rGO}+0.375 \mathrm{SPT}$ & 261 \\
\hline $\mathrm{B} / \mathrm{rGOC}-\mathrm{F}$ & 50 Chitosan + 50 CMC & - & $0.375 \mathrm{rGO}+0.375 \mathrm{CNCs}$ & 261 \\
\hline $\mathrm{BE} 2 / \mathrm{GOS}-\mathrm{F}$ & 50 Chitosan + $50 \mathrm{CMC}$ & 20 & $0.375 \mathrm{GO}+0.375 \mathrm{SPT}$ & 261 \\
\hline BE2/GOC-F & 50 Chitosan + 50 CMC & 20 & $0.375 \mathrm{GO}+0.375 \mathrm{CNCs}$ & 261 \\
\hline BE2/rGOS-F & 50 Chitosan + 50 CMC & 20 & $0.375 \mathrm{rGO}+0.375 \mathrm{SPT}$ & 261 \\
\hline $\mathrm{BE} 2 / \mathrm{rGOC}-\mathrm{F}$ & 50 Chitosan + 50 CMC & 20 & $0.375 \mathrm{rGO}+0.375 \mathrm{CNCs}$ & 261 \\
\hline
\end{tabular}


were supplied by Scientific Laboratory Supplies Ltd (UK). SPT and $\left[\mathrm{C}_{2} \mathrm{mim}\right][\mathrm{OAc}](\geq 95.0 \%)$ purchased from Sigma-Aldrich Company Ltd (UK). GO, in the form of aqueous paste $(25 \% \mathrm{GO}, 74 \%$ water, and $1-1.5 \% \mathrm{HCl})$, was acquired from Abalonyx AS (Norway). GO was chemically reduced into rGO using a hydrazine hydrate/ ammonia mixture solution at $90{ }^{\circ} \mathrm{C}$ following the protocol detailed in our previous publication [35]. CNCs were procured from Nanjing XFNANO Materials Tech Co., Ltd (China). Deionised water was used throughout the work.

\section{Preparation of chitosan-based composites}

The formulations of the different bionanocomposites prepared in this work are listed in Table 1. The biopolymer matrix was either chitosan alone (represented by "A") or a chitosan/CMC blend at 1:1 (w/w) ratio ("B"). The sample preparation procedure used was established previously [21], including pre-blending of the ingredients, thermomechanical kneading at $80^{\circ} \mathrm{C}$ for 15 min using a HAAKE Rheomix OS Lab Mixer (Thermo Fisher Scientific, USA), hot-pressing using a COLLIN P200 P/M platen press (COLLIN Lab \& Pilot Solutions GmbH, Germany) at $110{ }^{\circ} \mathrm{C}$ for $10 \mathrm{~min}$, and then stored at $57 \%$ relative humidity (RH) and room temperature (RT) for 3 weeks before characterisation. Throughout the discussion below the samples are compared with those reported previously, including $\mathrm{A} / \mathrm{S}-\mathrm{F}, \mathrm{A} / \mathrm{C}-\mathrm{F}, \mathrm{B} / \mathrm{S}-\mathrm{F}, \mathrm{B} / \mathrm{C}-\mathrm{F}$ (un-plasticised biopolymer matrices incorporating $\mathrm{SPT}$ or $\mathrm{CNCs}$ ), $\mathrm{AE} 2 / \mathrm{S}-\mathrm{F}, \mathrm{AE} 2 / \mathrm{C}-\mathrm{F}, \mathrm{BE} 2 / \mathrm{S}-\mathrm{F}, \mathrm{BE} 2 / \mathrm{C}-\mathrm{F}\left(\left[\mathrm{C}_{2} \mathrm{mim}\right][\mathrm{OAc}]-\right.$ plasticised matrices with SPT or CNCs) [36], A/GO-F, $\mathrm{A} / \mathrm{rGO}, \mathrm{B} / \mathrm{GO}-\mathrm{F}, \mathrm{B} / \mathrm{rGO}-\mathrm{F}$ (un-plasticised matrices with $\mathrm{GO}$ or GO) [35], AE2/GO-F, AE2/rGO, BE2/GO-F, and $\mathrm{BE} 2 / \mathrm{rGO}-\mathrm{F}\left(\left[\mathrm{C}_{2} \mathrm{mim}\right][\mathrm{OAc}]\right.$-plasticised matrices with GO or GO) [39], which were all prepared using the same procedure.

\section{Characterisation of chitosan-based composites}

The samples were characterised following the methods described previously [35]. Briefly, scanning electron microscopy (SEM) images of cryo-fractured sections of the bionanocomposite films were acquired using a ZEISS SIGMA field-emission gun microscope (Carl Zeiss AG, Germany) at $6 \mathrm{kV}$.

Ribbons obtained by ultramicrotoming of the bionanocomposite films were imaged in the mode of scanning transmission electron microscopy (STEM) using a Talos F200X transmission electron microscope (Thermo Fisher Scientific, USA) at $200 \mathrm{kV}$.

A Bruker TENSOR 27 Fourier-transform infrared (FTIR) spectrometer (Bruker Corporation, USA) coupled with an attenuated total reflection (ATR) accessory was used to collect FTIR spectra at RT with 32 scans for each sample over a range of $4000-500 \mathrm{~cm}^{-1}$.

X-ray diffraction (XRD) analysis was undertaken using a Panalytical Empyrean X-ray diffractometer (Malvern Panalytical Ltd, UK) at $40 \mathrm{kV}$ and $40 \mathrm{~mA}$ with a Co target $(\mathrm{K} \alpha=1.790307 \AA)$ and a beam slit of $10 \mathrm{~mm}$. The samples were scanned over an angular range $(2 \theta)$ of $6-40^{\circ}$ with a step size of $0.0263^{\circ}$ and a step rate of $2.16 \mathrm{~s} / \mathrm{step}$.

Thermo-gravimetric analysis (TGA) was conducted using a Mettler Toledo TGA (Mettler Toledo, USA) under temperature ramping from $30{ }^{\circ} \mathrm{C}$ to $700{ }^{\circ} \mathrm{C}$ at $10 \mathrm{~K} /$ min under nitrogen.

A Tritec 2000 DMA (Triton Technology Ltd, UK) was employed to perform dynamic mechanical thermal analysis (DMTA) in the dual cantilever mode (sample length: $5 \mathrm{~mm}$; displacement: $0.01 \mathrm{~mm}$ ) with temperature scans from $-100{ }^{\circ} \mathrm{C}$ to $180^{\circ} \mathrm{C}$ at $2 \mathrm{~K} / \mathrm{min}$ and $1 \mathrm{~Hz}$.

Following ASTM Standard D882, tensile tests of the specimens as thin sheets were conducted using an Instron 3367 Universal Testing System (Intron, USA) with a $1 \mathrm{kN}$ load cell at a constant crosshead speed of $3 \mathrm{~mm} / \mathrm{min}$.

Contact angle measurements were carried out based on the sessile-drop technique and the Young-Laplace equation using an Attension Theta Lite instrument (Biolin Scientific, UK). A drop $(2 \mu \mathrm{L})$ of distilled water was placed onto the sample surface with a manual dispenser and the images were recorded at RT over a time range of $60 \mathrm{~s}$ at $5.1 \mathrm{fps}$.

\section{Results and discussion}

Morphology and structure of chitosan-based composites SEM images (Figure S1) shows that all the bionanocomposite films had a cohesive structure. For the samples containing SPT, this needle-like nanofiller can be, observed as white dots or even as protruding rods. The SPT nanoparticles are more apparent in the samples that also contained rGO (A/rGOS-F, AE2/rGOS-F, B/rGOS$\mathrm{F}$, and $\mathrm{BE} 2 / \mathrm{rGOS}-\mathrm{F})$ than in those also included with $\mathrm{GO}$ (A/GOS-F, AE2/GOS-F, B/GOS-F, and BE2/GOS-F). In this regard, the hydrophilic GO may have assisted with the de-aggregation of SPT needles in the polysaccharide matrices, whether plasticised or not. However, there was no discernible difference in morphology between the samples with $\mathrm{rGO}+\mathrm{CNC}$ and those with $\mathrm{GO}+\mathrm{CNC}$ added.

The extent of nanofiller dispersion was also examined by STEM, see Fig. 1. For the bionanocomposites containing SPT, this non-swelling, needle-like clay was clearly identifiable in the STEM images. Some individual needles had lengths up to several hundreds of nanometres (e.g. in A/GOS-F), whereas some large agglomerates can also be 
seen (e.g. in B/GOS-F). It is likely that most of the GO or rGO was finely dispersed and not observable under STEM, while some could be barely observed as agglomerations (A/rGOC-F) or a "cloudy" feature intermixed with SPT nanoneedles (A/GOS-F, AE2/GOS-F, B/GOS$\mathrm{F}$, and BE2/GOS-F) as indicated by blue arrows. This 3D interconnected microstructure formed by $2 \mathrm{D} \mathrm{GO}$ and 1D SPT could indicate strong hydrogen-bonding interaction between these two hydrophilic nanomaterials. This strong interaction can facilitate nanofiller dispersion in a polymer matrix and lead to a 3D interconnected microstructure formed by two nanofillers [37]. Strong interaction may also occur between GO and CNCs although $\mathrm{CNCs}$ were much less visible under STEM here. This feature of 3D interconnected microstructure could hardly be identified for the samples into which SPT and hydrophobic rGO were added together. Overall, effective dispersion of the nanofillers resulted from thermomechanical mixing.

Figure 2 shows that the FTIR spectra for the different bionanocomposite films were similar to those for A-F and B-F (un-plasticised chitosan and chitosan/CMC without nanofiller) [21] despite some shifting of bands. Our previous work [35] indicated that in A/GO-F, the interactions between $\mathrm{GO}$ and chitosan resulted in shifting of the bands originally at $1256 \mathrm{~cm}^{-1}, 1065 \mathrm{~cm}^{-1}$, and $1022 \mathrm{~cm}^{-1}$, which can be assigned to amide III, the asymmetric $\mathrm{C}-\mathrm{O}-\mathrm{C}$ stretching in the glycosidic linkage, and the skeletal vibration of $\mathrm{C}-\mathrm{O}$ stretching, respectively [40-42], while these changes were not apparent for A/rGO-F. Besides, A/C-F had a red shift of the band originally at $1065 \mathrm{~cm}^{-1}$, indicating strong interaction between $\mathrm{CNCs}$ and chitosan, while A/S-F showed an unchanged FTIR spectrum [36]. Here, we found $\mathrm{A} / \mathrm{GOC}-\mathrm{F}$ had band positions unchanged to those for A/GO-F, whereas the band positions for A/ GOS-F match those for A-F. In this regard, there are strong interactions between 2D GO and 1D SPT, which compete with and weaken the interaction of GO with chitosan. This supports the observations made from the STEM images (i.e. the formation of a 3D interconnected microstructure). CNCs did not have such a strong effect as SPT did in weakening GO-chitosan interactions. A/ rGOS-F and A/rGOC-F did not display any band shifting compared with $\mathrm{A} / \mathrm{rGO}-\mathrm{F}$ and $\mathrm{A}-\mathrm{F}$. In this regard, $\mathrm{rGO}$ even hindered interaction between $\mathrm{CNCs}$ and chitosan.
Most of the A-series of bionanocomposites plasticised by $\left[\mathrm{C}_{2} \mathrm{mim}\right][\mathrm{OAc}]$ showed the same FTIR patterns to that for A-F without discernible shifting of bands. There are strong interactions between the IL and chitosan such that the nanofillers had a reduced impact on the polysaccharide chain interactions, which is not detectable by FTIR. Nonetheless, AE2/rGOC-F displayed a blue shift of the band originally at $1572 \mathrm{~cm}^{-1}$ (due to $\mathrm{N}-\mathrm{H}$ bending from amine and amide II) [40-42], possibly indicating a greater level of interaction of chitosan with the nanofillers in this case.

We previously found that, compared with B-F, B/ GO-F showed a slight blue shift of the band originally at $1022 \mathrm{~cm}^{-1}$ (ascribed to the skeletal vibration of $\mathrm{C}-\mathrm{O}$ stretching) [35] while B/S-F and B/C-F showed no significant changes [36]. Here, Fig. 2 shows that B/GOC-F and $\mathrm{B} / \mathrm{GO}-\mathrm{F}$ had the same band positions, whereas B/GOS-F had band positions matching those for B-F. This result indicates, again, the strong interaction between 1D SPT and 2D GO. Compared with B-F, inclusion of rGO + SPT or $\mathrm{rGO}+\mathrm{CNCs}$ also did not cause significant changes in the FITR spectrum.

The B-series of bionanocomposites plasticised by the IL showed the same FTIR patterns to that for B-F without apparent band shifting, except that BE2/GOC-F had a slight blue shift of the band at $1022 \mathrm{~cm}^{-1}$. Regarding the latter, CNCs may further interfere with the polysaccharide backbone vibration.

The crystalline structures of the different bionanocomposite films were examined using XRD, see Fig. 3. For all the A-series samples, the XRD curves were completely different from that for the original chitosan [21] and thus represent a predominantly re-crystallised chitosan structure. Compared with A/GO-F and A/rGO-F [35], the bionanocomposites with $\mathrm{GO}+\mathrm{SPT}$ or $\mathrm{GO}+\mathrm{CNCs}$ added exhibited a similar XRD pattern. While A/GOC-F showed almost the same peak intensities as those for A/ GO-F, for A/GOS-F the XRD peaks (especially at $13.5^{\circ}$ ) became more intense. In A/GOS-F, strong interaction between 2D GO and 1D SPT (as suggested from STEM and FTIR analyses) could reduce the effect the nanofillers have on chitosan chain re-arrangement during postprocessing conditioning, leading to a greater degree of re-crystallisation. Nevertheless, in A/GOC-F, the CNCs did not have such a strong interaction with GO, nor did it show an additional effect on chitosan re-crystallisation. Moreover, $\mathrm{A} / \mathrm{rGOS}-\mathrm{F}$ and $\mathrm{A} / \mathrm{rGOC}-\mathrm{F}$ displayed less

(See figure on next page.)

Fig. 1 Scanning transmission electron microscopy high-angle annular dark-field (STEM-HAADF) images of the different chitosan and chitosan/ carboxymethyl cellulose (CMC)-based nanocomposite films. The yellow arrows indicate a feature possibly due to CNCs not fully dispersed in the matrix; the blue arrows indicate 3D microstructural domains formed by SPT and GO. The scale bar for the first and third column of images (magnification $31.8 \mathrm{k} \times$ ) represents $500 \mathrm{~nm}$ and the scale bar for the second and fourth column of images (magnification $180 \mathrm{k} \times$ ) represents $100 \mathrm{~nm}$ 

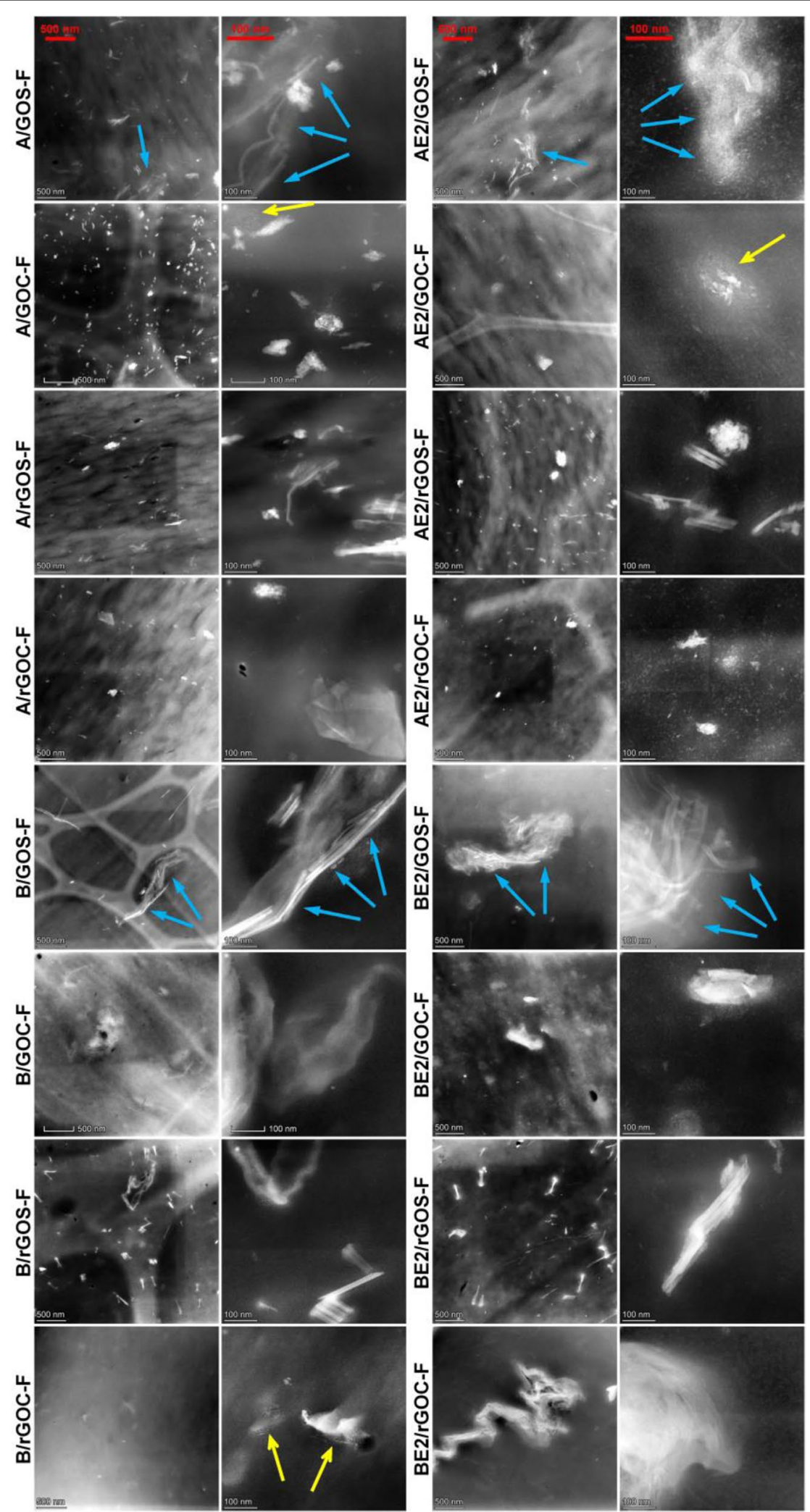

Fig. 1 (See legend on previous page.) 

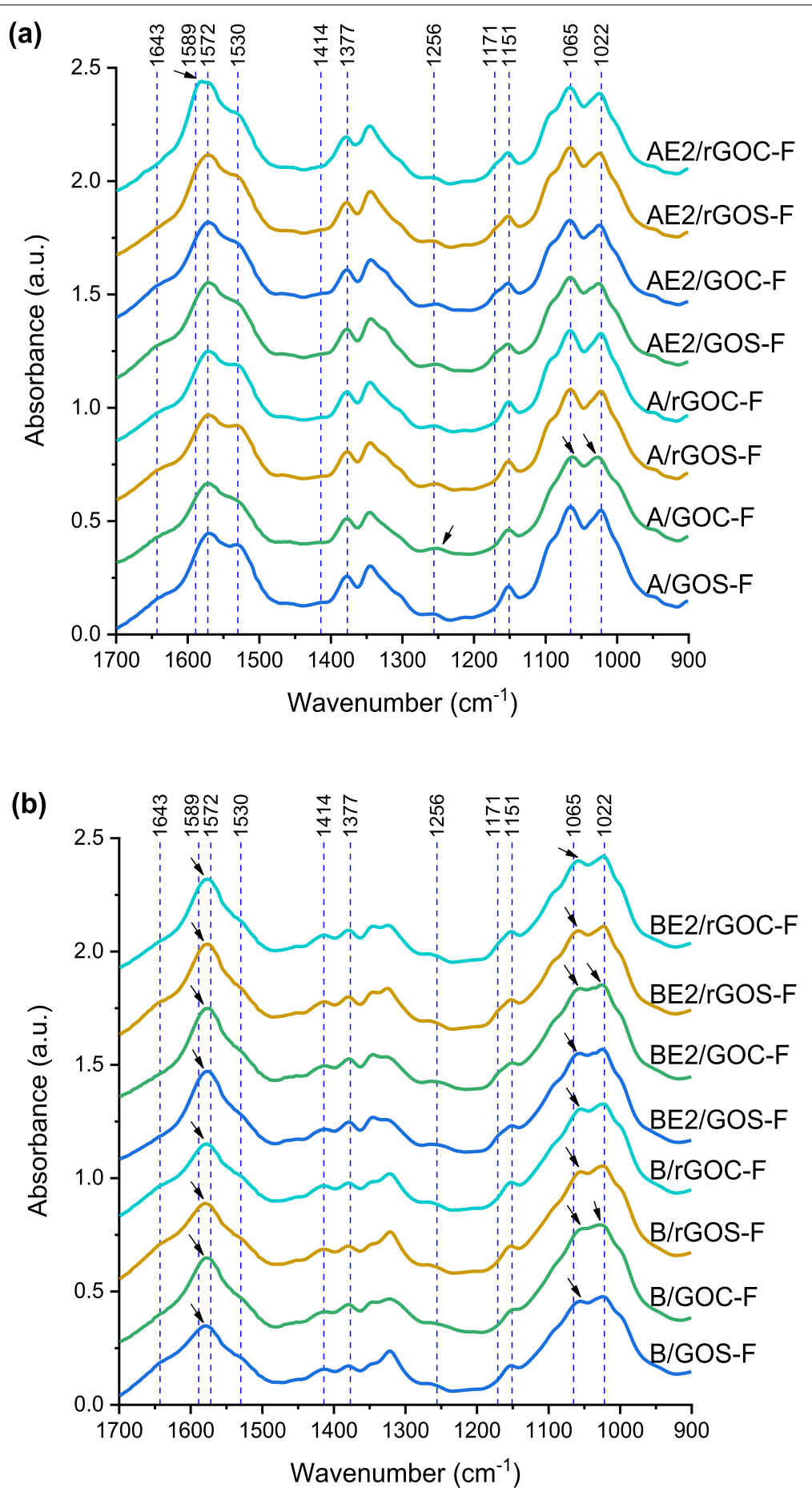

Fig. 2 Fourier-transform infrared (FTIR) spectra for the different a chitosan and $\mathbf{b}$ chitosan/carboxymethyl cellulose (CMC)-based nanocomposite films. The reference lines denotes characteristic bands $1171 \mathrm{~cm}^{-1}$ for [C $\left.\operatorname{mim}\right][O A c]$ [39], 1589, 1414 and $1022 \mathrm{~cm}^{-1}$ for CMC, 1643, 1572, 1530, 1377, $1256,1151,1065$, and $1022 \mathrm{~cm}^{-1}$ for chitosan [21]. The arrows signify peak shifting or peak intensity change

intense peak intensities (especially at $13.5^{\circ}$ ) than those for $\mathrm{A} / \mathrm{rGO}-\mathrm{F}$ but more intense than those for A/GO-F and A/GOC-F. Our previous study [36] showed that SPT and CNCs suppressed the re-crystallisation of chitosan. Here, in $\mathrm{A} / \mathrm{rGOS}-\mathrm{F}$ and $\mathrm{A} / \mathrm{rGOC}-\mathrm{F}$, inclusion of SPT and CNCs may still have some effect in limiting chitosan 

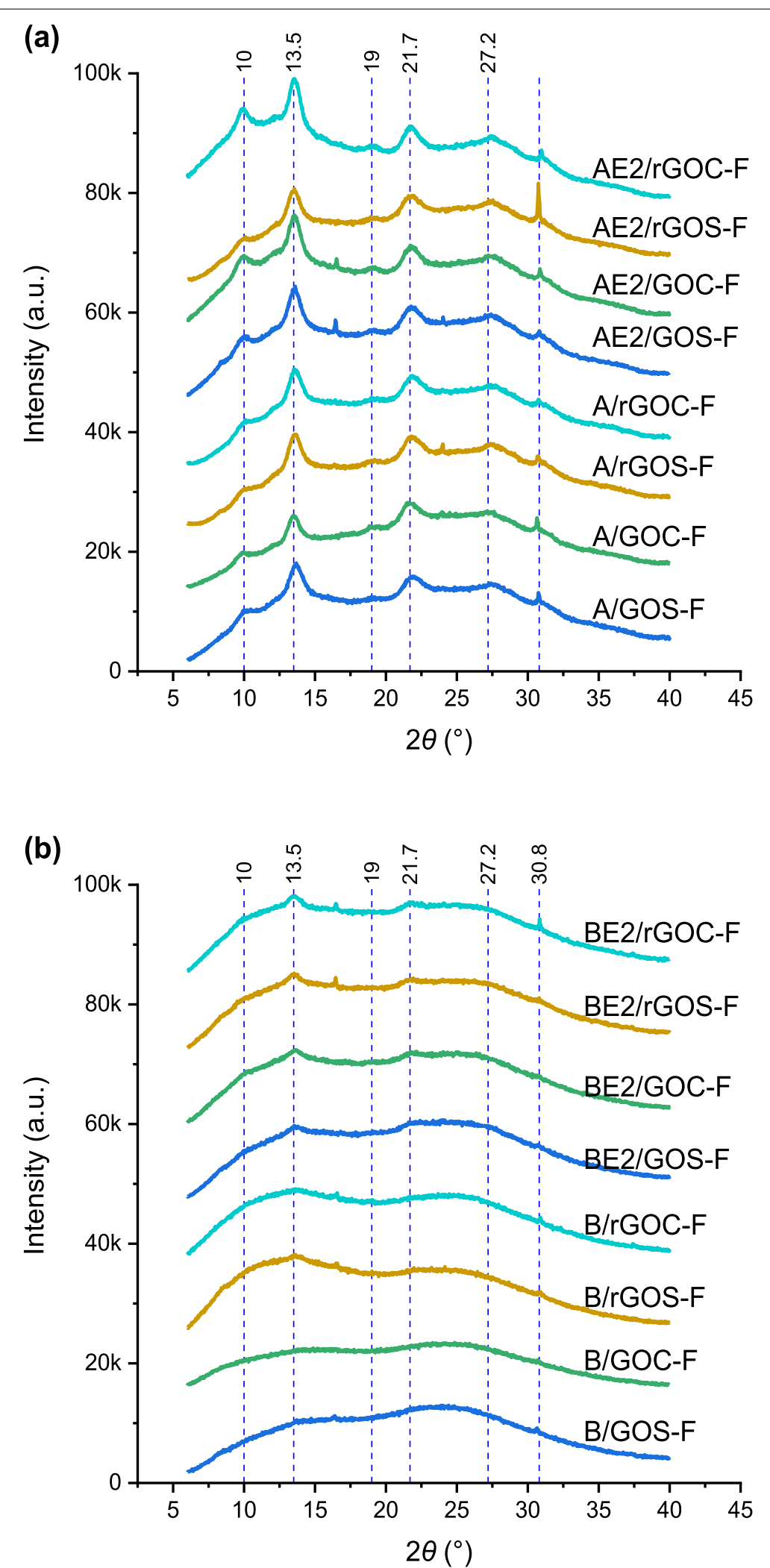

Fig. 3 X-ray diffractograms for the different $\mathbf{a}$ chitosan and $\mathbf{b}$ chitosan/carboxymethyl cellulose (CMC)-based nanocomposite films 
chain rearrangement for re-crystallisation, although this behaviour was not as strong as that for GO.

The A-series of bionanocomposites plasticised by $\left[\mathrm{C}_{2} \mathrm{mim}\right][\mathrm{OAc}]$ showed similar XRD curves as those for $\mathrm{AE} 2 / \mathrm{GO}-\mathrm{F}$ and $\mathrm{AE} 2 / \mathrm{rGO}-\mathrm{F}$ [39], suggesting their crystalline structure was mainly determined by the IL.

All the un-plasticised $\mathrm{B}$-series of bionanocomposites were predominantly amorphous. While $\left[\mathrm{C}_{2} \mathrm{mim}\right][\mathrm{OAc}]$ plasticisation was found to result in a slight increase in polysaccharide crystallinity [39], here, inclusion of nanofillers did not cause discernible differences in the XRD peak intensities.

\section{Properties of chitosan-based composites}

The thermal stability of the different samples was analysed by TGA and presented as derivative-weight profiles, see Fig. 4. Typically, chitosan materials display a major weight loss between $200{ }^{\circ} \mathrm{C}$ and $400{ }^{\circ} \mathrm{C}$, along with a small, sharp peak centred between about $200{ }^{\circ} \mathrm{C}$ and $240{ }^{\circ} \mathrm{C}$, attributed to the initial de-polymerisation of chitosan [21]. Our previous study [35] showed that, for the un-plasticised A-matrix, inclusion of GO reduced the major peak temperature $\left(T_{\mathrm{d}}\right)$ (from $297^{\circ} \mathrm{C}$ for A-F to $289^{\circ} \mathrm{C}$ for A/GO-F) while, rGO enhanced thermal stability $\left(T_{\mathrm{d}}=307^{\circ} \mathrm{C}\right.$ for $\left.\mathrm{A} / \mathrm{rGO}-\mathrm{F}\right)$. Moreover, the $T_{\mathrm{d}}$ values of $\mathrm{A} / \mathrm{S}-\mathrm{F}$ and $\mathrm{A} / \mathrm{C}$-F were $280{ }^{\circ} \mathrm{C}$ and $289^{\circ} \mathrm{C}$, respectively, that is, inclusion of SPT or CNCs reduced the thermal stability of chitosan [36]. Here, A/GOC showed similar $T_{\mathrm{d}}$ as that for A/GO-F $\left(291{ }^{\circ} \mathrm{C}\right)$. Nevertheless, as the $T_{\mathrm{d}}$ value of A/GOS-F $\left(312{ }^{\circ} \mathrm{C}\right)$ was significantly higher than that of $\mathrm{A} / \mathrm{GO}-\mathrm{F}$ and $\mathrm{A} / \mathrm{S}-\mathrm{F}$, it may be there is a synergistic effect of combining 1D SPT and 2D GO together yielding enhanced thermal stability. This could be due to the greater dispersion of SPT facilitated by interacting with GO (see the 3D interconnected microstructure in STEM images). Both SPT and GO could restrict the transfer of pyrolysis products through the matrix. The higher thermal stability of A/GOS-F also corresponds to higher crystallinity (see XRD results). Furthermore, compared with $\mathrm{A} / \mathrm{rGO}-\mathrm{F}, \mathrm{A} / \mathrm{rGOC}-\mathrm{F}$ had a similar $T_{\mathrm{d}}$ value, while A/rGOS-F displayed slightly enhanced thermal stability $\left(T_{\mathrm{d}}=310^{\circ} \mathrm{C}\right)$, which can also indicate a synergistic effect of 2D rGO and 1D SPT when combined.

Compared with AE2/GO-F $\left(T_{\mathrm{d}}=276{ }^{\circ} \mathrm{C}\right)$ [39], AE2/ GOS-F and AE2/GOC-F showed similar thermal stability. The thermal stability of AE2/rGOS-F was unchanged as was AE2/rGO-F $\left(T_{\mathrm{d}}=282{ }^{\circ} \mathrm{C}\right)$, while the $T_{\mathrm{d}}$ value of AE2/rGOC-F $\left(273{ }^{\circ} \mathrm{C}\right)$ was notably lower and similar to the $T_{\mathrm{d}}$ of AE2-F $\left(272{ }^{\circ} \mathrm{C}\right)$ [39]. Our previous study [36] noted the slightly higher thermal stability of AE2/C-F $\left(T_{\mathrm{d}}=275^{\circ} \mathrm{C}\right)$ over that of AE2-F $\left(T_{\mathrm{d}}=272^{\circ} \mathrm{C}\right)$. It should be noted that the $T_{\mathrm{d}}$ value of $\left[\mathrm{C}_{2} \mathrm{mim}\right][\mathrm{OAc}]\left(252^{\circ} \mathrm{C}\right)$ was lower than that of chitosan [39]. Thus, we speculate that, for AE2/rGOC-F, the thermal stability of chitosan was more affected by the IL, while a combination of rGO and $\mathrm{CNCs}$ could disrupt chitosan chain interactions further. This phenomenon was further investigated.

$\mathrm{B} / \mathrm{GO}-\mathrm{F}$ had two overlapping peaks at $269^{\circ} \mathrm{C}$ (major, $T_{\mathrm{d}}$ ) and $297^{\circ} \mathrm{C}$ (minor); the peak at the higher temperature could be attributed to the ionically complexed polysaccharide structure [21]. Compared with B/GO-F, while $B / G O C-F$ only showed some decrease in temperature of the second peak, B/GOS-F displayed a broadened transition up to about $350{ }^{\circ} \mathrm{C}$, which is most probably derived from multiple thermal decomposition events, with $T_{\mathrm{d}}=260^{\circ} \mathrm{C}$. Conceivably, the interaction between $2 \mathrm{D}$ GO and 1D SPT resulted in a less homogenous polysaccharide structure. Compared with $\mathrm{B} / \mathrm{rGO}-\mathrm{F}\left(T_{\mathrm{d}}=268{ }^{\circ} \mathrm{C}\right)$, the thermal stability of $\mathrm{B} / \mathrm{rGOC}-\mathrm{F}$ was unchanged, whereas $\mathrm{B} / \mathrm{rGOS}-\mathrm{F}$ had significantly higher $T_{\mathrm{d}}\left(278^{\circ} \mathrm{C}\right)$. Our previous study [36] indicated that inclusion of SPT alone did not alter the thermal stability of the unplasticised B-matrix. Nonetheless, here the addition of SPT resulted in increased thermal stability when it was included with rGO.

The B-series of bionanocomposites plasticised by $\left[\mathrm{C}_{2} \mathrm{mim}\right][\mathrm{OAc}]$ exhibited a more defined peak, just as $\mathrm{BE} 2-\mathrm{F}$, possibly due to enhanced interaction between the two polysaccharides by $\left[\mathrm{C}_{2} \mathrm{mim}\right][\mathrm{OAc}]$ [39]. BE2/GOS and $\mathrm{BE} 2 / \mathrm{GOC}$ had unchanged $T_{\mathrm{d}}$ values and similar to that of BE2/GO-F and BE2-F $\left(T_{\mathrm{d}}=283{ }^{\circ} \mathrm{C}\right)$ [39]. Nonetheless, BE2/rGOS-F and BE2/rGOC-F had a $T_{\mathrm{d}}$ value of $290{ }^{\circ} \mathrm{C}$, higher than that of BE2/rGO-F $\left(284{ }^{\circ} \mathrm{C}\right)$, as well as those of BE2-F, BE2/S-F, and BE2/C-F (all $283{ }^{\circ} \mathrm{C}$ ) [36, 39]. This observation suggests there is a synergistic effect on inclusion of $\mathrm{rGO}+\mathrm{SPT}$ or $\mathrm{rGO}+\mathrm{CNCs}$ resulting in enhanced thermal stability of the IL-plasticised B-matrix, possibly by enhancing ionic complexation as well as effectively restricting the transfer of pyrolysis products by forming tortuous paths for diffusion.

Generally, chitosan materials have two relaxation events, namely $\alpha$-transition (glass transition) and $\beta$-relaxation, that can be revealed by DMTA $[43,44]$. These two relaxations were also shown here on loss tangent $(\tan \delta)$ curves for all the bionanocomposites, see Fig. 5. For A/GO-F, the peak temperature of the $\alpha$-transition $\left(T_{\alpha}\right)$ was $109^{\circ} \mathrm{C}$ and for the $\beta$-transition $\left(T_{\beta}\right)$ at $-34{ }^{\circ} \mathrm{C}$ [35]. A/GOC-F displayed a $\tan \delta$ profile resembling that for A/GO-F with no significant changes in $T_{\alpha}$ and $T_{\beta}$. This means inclusion of $\mathrm{GO}+\mathrm{CNCs}$ did not alter the molecular interactions in amorphous chitosan. Nonetheless, for A/GOS-F, the $\alpha$-transition was less intense accompanied by lower $T_{\alpha}\left(103{ }^{\circ} \mathrm{C}\right)$. The $T_{\alpha}$ value of A/ GOS-F is also lower than that of A/S-F $\left(112^{\circ} \mathrm{C}\right)$ [36]. The reduction in $T_{\alpha}$ for A/GOS-F could be due to the strong interaction between 2D GO and 1D SPT, as discussed 


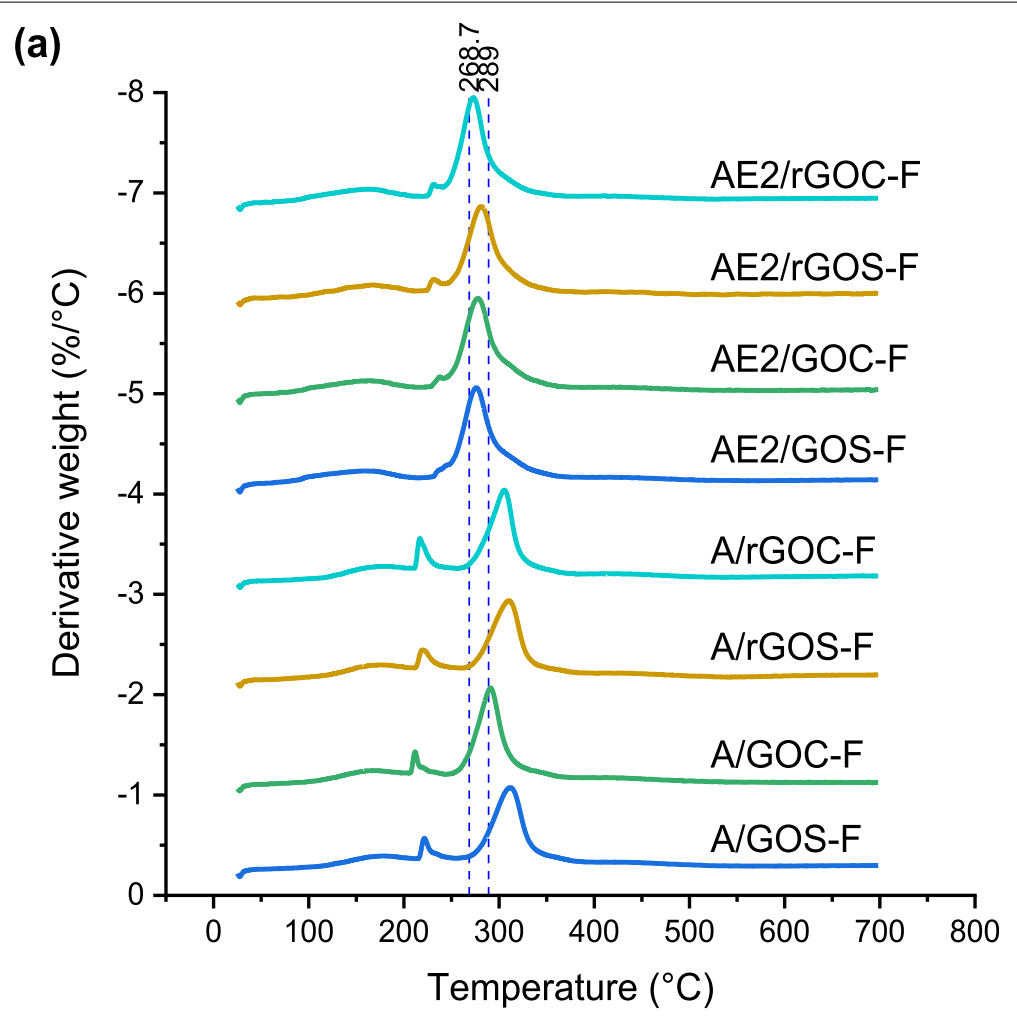

(b)

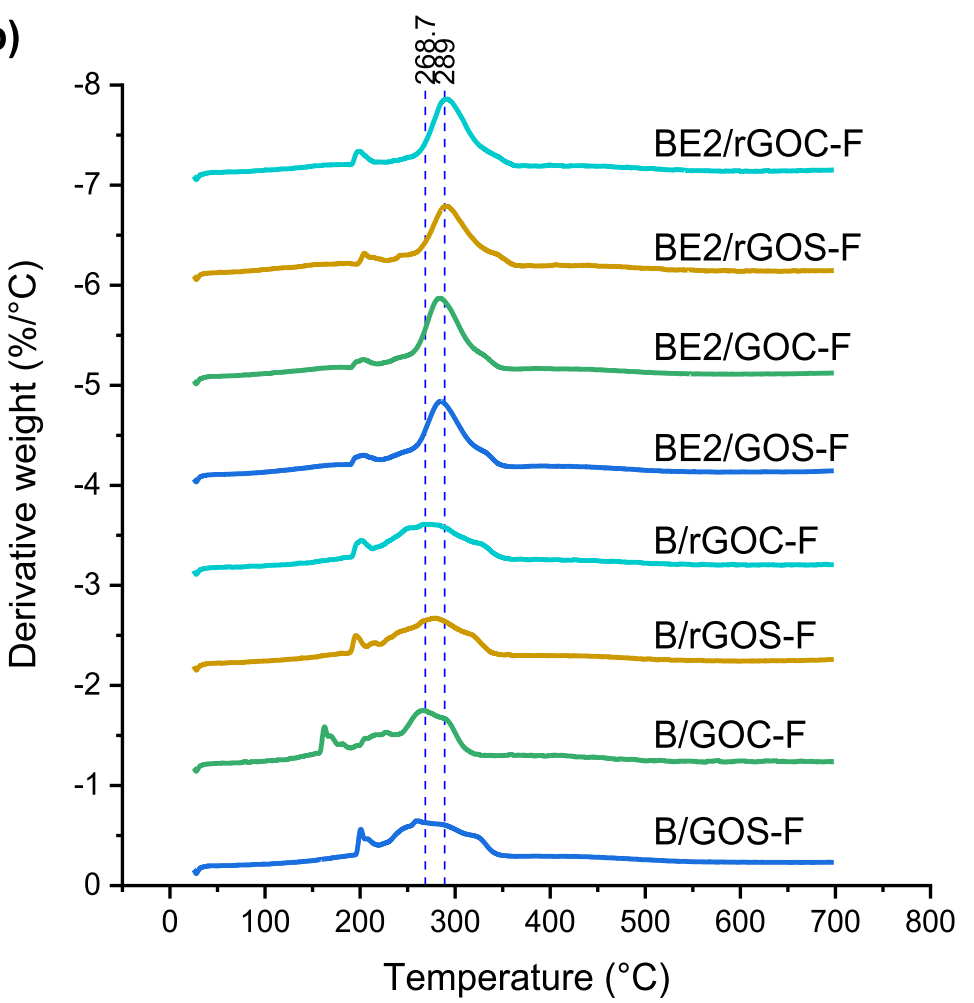

Fig. 4 Thermogravimetric analysis (TGA) results (derivative weight vs. temperature) for the different a chitosan and $\mathbf{b}$ chitosan/carboxymethyl cellulose (CMC)-based nanocomposite films. The reference lines denote the major peak temperatures of $B / G O-F\left(269^{\circ} \mathrm{C}\right)$ and $A / G O-F\left(289^{\circ} \mathrm{C}\right)$, respectively [21] 

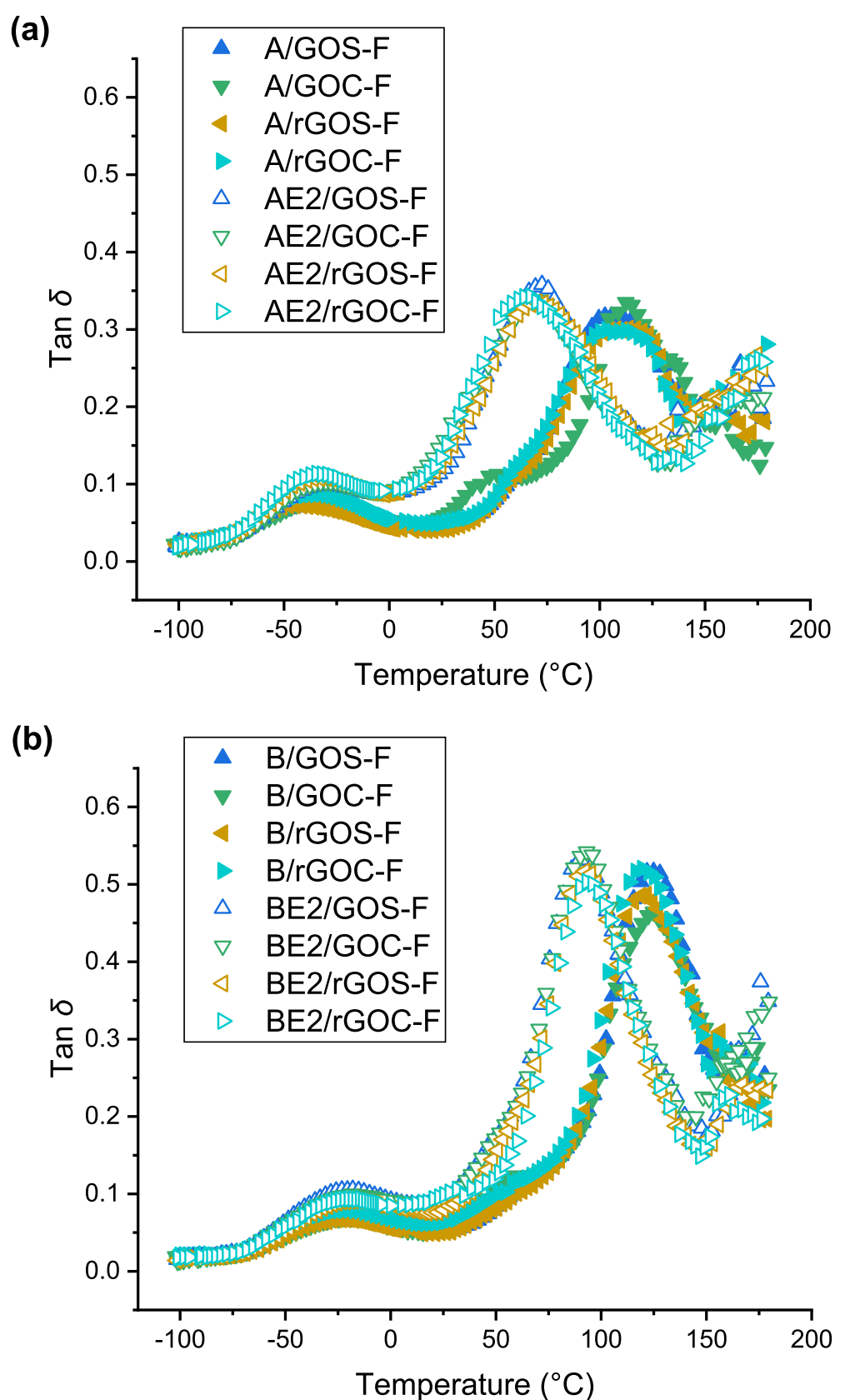

Fig. 5 Dynamic mechanical thermal analysis (DMTA) results (loss tangent (tan $\delta$ ) vs. temperature) for the different $\mathbf{a}$ chitosan and $\mathbf{b}$ chitosan/ carboxymethyl cellulose (CMC)-based nanocomposite films

above. Moreover, A/rGO-F [35], A/rGOS-F, and A/ rGOC-F exhibited a $\tan \delta$ profile very similar to that of A/GOS-F. In these samples, the interaction between rGO and chitosan chains could be weak and the effect of SPT or CNCs might be hindered by the presence of the rGO nanosheets.
Our previous study [36] showed that $\mathrm{AE} 2 / \mathrm{S}-\mathrm{F}$ and AE2/C-F had the same $T_{\beta}\left(-28{ }^{\circ} \mathrm{C}\right)$ and $T_{\alpha}\left(73{ }^{\circ} \mathrm{C}\right)$ as those for AE2-F. In comparison with AE2/GO-F $\left(T_{\beta}=-30{ }^{\circ} \mathrm{C}\right.$ and $T_{\alpha}=70{ }^{\circ} \mathrm{C}$ ) [39], here, AE2/GOS-F and AE2/GOC-F showed no significant changes in either $T_{\beta}$ or $T_{\alpha}$. In these samples, chitosan chain mobility 
is mainly influenced by the IL. Compared with AE2/ rGO-F $\left(T_{\beta}=-32{ }^{\circ} \mathrm{C}\right.$ and $\left.T_{\alpha}=74{ }^{\circ} \mathrm{C}\right)$ [39], AE2/rGOS-F and AE2/rGOC-F displayed moderately lower $T_{\alpha}\left(69^{\circ} \mathrm{C}\right.$ and $65{ }^{\circ} \mathrm{C}$, respectively). Regarding the increased chain mobility in these two bionanocomposites as shown here, the inclusion of a combination of $\mathrm{rGO}+\mathrm{CNCs}$ or $\mathrm{rGO}+\mathrm{SPT}$ disrupted chain interactions, as discussed above and, facilitate the plasticisation of chitosan by the IL. This interesting phenomenon is worth further investigation.

Our previous research $[35,36]$ also indicated that inclusion of nanofillers such as CNCs and SPT further limited chain mobility of the un-plasticised B-matrix by interacting with the polysaccharides. $\mathrm{B} / \mathrm{S}-\mathrm{F}$ and $\mathrm{B} / \mathrm{C}-\mathrm{F}$ had $T_{\beta}=-19{ }^{\circ} \mathrm{C}$ and $-18{ }^{\circ} \mathrm{C}$ and $T_{\alpha}=126{ }^{\circ} \mathrm{C}$ and $125^{\circ} \mathrm{C}$ [36]. Compared with B/GO-F $\left(T_{\beta}=-24{ }^{\circ} \mathrm{C}\right.$ and $T_{\alpha}=120^{\circ} \mathrm{C}$ ) [35], B/GOS-F and B/GOC-F had moderately higher $T_{\alpha}$ (both $125^{\circ} \mathrm{C}$ ) while $T_{\beta}$ was unchanged. In this regard, inclusion of GO + SPT and GO + CNCs constrained polysaccharide chain mobility with the effects of the individual nanofillers. Nonetheless, compared with B/rGO-F $\left(T_{\beta}=-25^{\circ} \mathrm{C}\right.$ and $\left.T_{\alpha}=121{ }^{\circ} \mathrm{C}\right)$ [35], B/rGOS-F and $\mathrm{B} / \mathrm{rGOC}-\mathrm{F}$ showed no discernible changes to relaxation temperatures. In this instance, the rGO nanosheets may have hindered the effects of CNCs or SPT.

BE2-F had $T_{\beta}=-23{ }^{\circ} \mathrm{C}$ and $T_{\alpha}=91{ }^{\circ} \mathrm{C}$ [39]. Inclusion of GO or rGO, or either of them combined with SPT or $\mathrm{CNCs}$, generally did not cause apparent changes in the relaxation temperatures, suggesting the dominant effect of the IL.

Representative stress-strain curves under tensile testing (Figure S2) show that all the different bionanocomposite films were tough materials and most samples displayed strain-hardening behaviour, with the exception of B/GOC-F, behaviour displayed just like B/GO-F [35]. This may suggest, in these most amorphous samples, the polysaccharide chains were less entangled. We can also notice that AE2/rGOC-F was the most ductile sample supporting the hypothesis that the combination of $\mathrm{rGO}+\mathrm{CNCs}$ enhanced the $\left[\mathrm{C}_{2} \mathrm{mim}\right][\mathrm{OAc}]$ plasticisation of chitosan.

Figure 6 shows the Young's modulus $(E)$, tensile strength $\left(\sigma_{\mathrm{t}}\right)$, and elongation at break $\left(\varepsilon_{\mathrm{b}}\right)$ of the different samples. Compared with A/GO-F $(E=1723 \pm 59 \mathrm{MPa}$ and $\sigma_{\mathrm{t}}=55.7 \pm 1.0 \mathrm{MPa}$ ), both A/GOS-F and A/GOC-F showed lower $E(1424 \pm 169$ and $1453 \pm 202)$ and $\mathrm{A} /$ GOC-F also had reduced $\sigma_{\mathrm{t}}(51.5 \pm 5 \mathrm{MPa}) . \mathrm{GO}$ as a $2 \mathrm{D}$ material was shown to have a greater reinforcement than 1D SPT and CNCs $[35,36]$. The results here suggest a change in property on addition of two nanofillers. Compared with A/rGO-F $(E=1489 \pm 135 \mathrm{MPa}$ and $\sigma_{\mathrm{t}}=57.7 \pm 1.1 \mathrm{MPa}$ ) [35], A/rGOC-F had similar mechanical properties while A/rGOS-F had a higher $E$ $(1635 \pm 97 \mathrm{MPa})$ and $\sigma_{\mathrm{t}}(60.7 \pm 1.4 \mathrm{MPa})$. As inclusion of SPT alone could not result in the apparent changes in mechanical properties [36], this result clearly indicates some synergistic effect of the combined inclusion of $1 \mathrm{D}$ SPT and 2D rGO in enhancing mechanical properties.

Compared with AE2/GO-F $\quad(E=751 \pm 52 \mathrm{MPa}$, $\sigma_{\mathrm{t}}=25.1 \pm 1.0 \mathrm{MPa}$, and $\left.\varepsilon_{\mathrm{b}}=47.1 \pm 11.6 \%\right)$ [39], AE2/ GOS-F had similar mechanical properties; AE2/GOC-F also had similar $E$ and $\sigma_{\mathrm{t}}$ but higher $\varepsilon_{\mathrm{b}}(66.1 \pm 15.6)$. Compared with AE2/rGO-F $\quad(E=1011 \pm 68 \mathrm{MPa}$, $\sigma_{\mathrm{t}}=28.8 \pm 2.9 \mathrm{MPa}$, and $\left.\varepsilon_{\mathrm{b}}=61.1 \pm 13.3 \%\right) \quad[39], \mathrm{AE} 2 /$ rGOS-F and AE2/rGOC-F had reduced $E(893 \pm 53 \mathrm{MPa}$ and $702 \pm 92 \mathrm{MPa}$, respectively) and $\sigma_{\mathrm{t}}(26.4 \pm 2.1 \mathrm{MPa}$ and $22.4 \pm 1.4 \mathrm{MPa}$, respectively) but increased $\varepsilon_{\mathrm{b}}$ $(78.2 \pm 12.2 \%$, and $76.5 \pm 20.0 \%$, respectively). Even compared with AE2/C-F $\left(\sigma_{\mathrm{t}}=26.0 \pm 1.4 \mathrm{MPa} ; \varepsilon_{\mathrm{b}}=53.1 \pm 7.4\right)$ [36], both AE2/GOC-F and AE2/rGOC-F had higher $\varepsilon_{\mathrm{b}}$ and AE2/rGOC-F had additionally lower $\sigma_{\mathrm{t}}$. This could reflect greater plasticisation of chitosan by the IL in the presence of $\mathrm{CNCs}+\mathrm{GO}$ or $\mathrm{CNCs}+\mathrm{rGO}$, as discussed above.

Among all the samples, B/GOS-F had the highest $E$ $(1926 \pm 121 \mathrm{MPa})$ and $\sigma_{\mathrm{t}}(77.5 \pm 1.2 \mathrm{MPa})$, which are much higher than those of $\mathrm{B} / \mathrm{S}-\mathrm{F}(E=1042 \pm 180 \mathrm{MPa}$ and $\left.\sigma_{\mathrm{t}}=57.4 \pm 4.1 \quad \mathrm{MPa}\right) \quad[36]$ and B/GO-F $\left(E=1047 \pm 270 \mathrm{MPa}\right.$ and $\left.\sigma_{\mathrm{t}}=61.3 \pm 4.5 \mathrm{MPa}\right)$ [35]. These enhanced mechanical properties could be due to a cooperative effect of $2 \mathrm{D}$ GO and 1D SPT when combined for load transfer within the predominantly amorphous B-matrix. This synergistic effect may be due to the 3D interconnected structure formed by GO $+\mathrm{SPT}$ and their excellent dispersion as shown from STEM images. In contrast, $\mathrm{B} / \mathrm{GOC}-\mathrm{F}$ displayed $E, \sigma_{\mathrm{t}}$, and $\varepsilon_{\mathrm{b}}$ much closer to those for $\mathrm{B} / \mathrm{GO}-\mathrm{F}$, suggesting $\mathrm{GO}$ had a greater effect than $\mathrm{CNCs}$ on the mechanical properties of the B-matrix. $\mathrm{B} / \mathrm{rGOS}-\mathrm{F}$ and $\mathrm{B} / \mathrm{rGOC}-\mathrm{F}$ had $E, \sigma_{\mathrm{t}}$ and $\varepsilon_{\mathrm{b}}$ values between those for $\mathrm{B} / \mathrm{rGO}-\mathrm{F}$ [35] and those for $\mathrm{B} / \mathrm{S}-\mathrm{F}$ or $\mathrm{B} / \mathrm{C}-\mathrm{F}$ [36], indicating there was no cooperation between $\mathrm{rGO}$ and SPT or CNCs with regard to the mechanical reinforcement of the B-matrix.

BE2/GOS-F and BE/GOC-F had similar $E, \sigma_{\mathrm{t}}$, and $\varepsilon_{\mathrm{b}}$ as those for BE2/GO-F $(E=863 \pm 81 \mathrm{MPa}$, $\sigma_{\mathrm{t}}=37.4 \pm 2.1 \mathrm{MPa}$, and $\varepsilon_{\mathrm{b}}=23.2 \pm 10.9 \mathrm{MPa}$ ) [39]. Also, $\mathrm{BE} 2 / \mathrm{rGOS}-\mathrm{F}$ and $\mathrm{BE} / \mathrm{rGOC}-\mathrm{F}$ had similar mechanical properties as those for BE2/rGO-F $(E=1018 \pm 100 \mathrm{MPa}$, $\sigma_{\mathrm{t}}=39.8 \pm 2.5 \mathrm{MPa}$, and $\varepsilon_{\mathrm{b}}=35.8 \pm 9.4 \mathrm{MPa}$ ) [39]. In these samples, the mechanical properties are mainly determined by the IL and the contributions of the nanofillers (especially CNCs or SPT) were minor.

The Shore D hardness for the different samples (see Figure S3) generally match the trends observed for $E$ and 

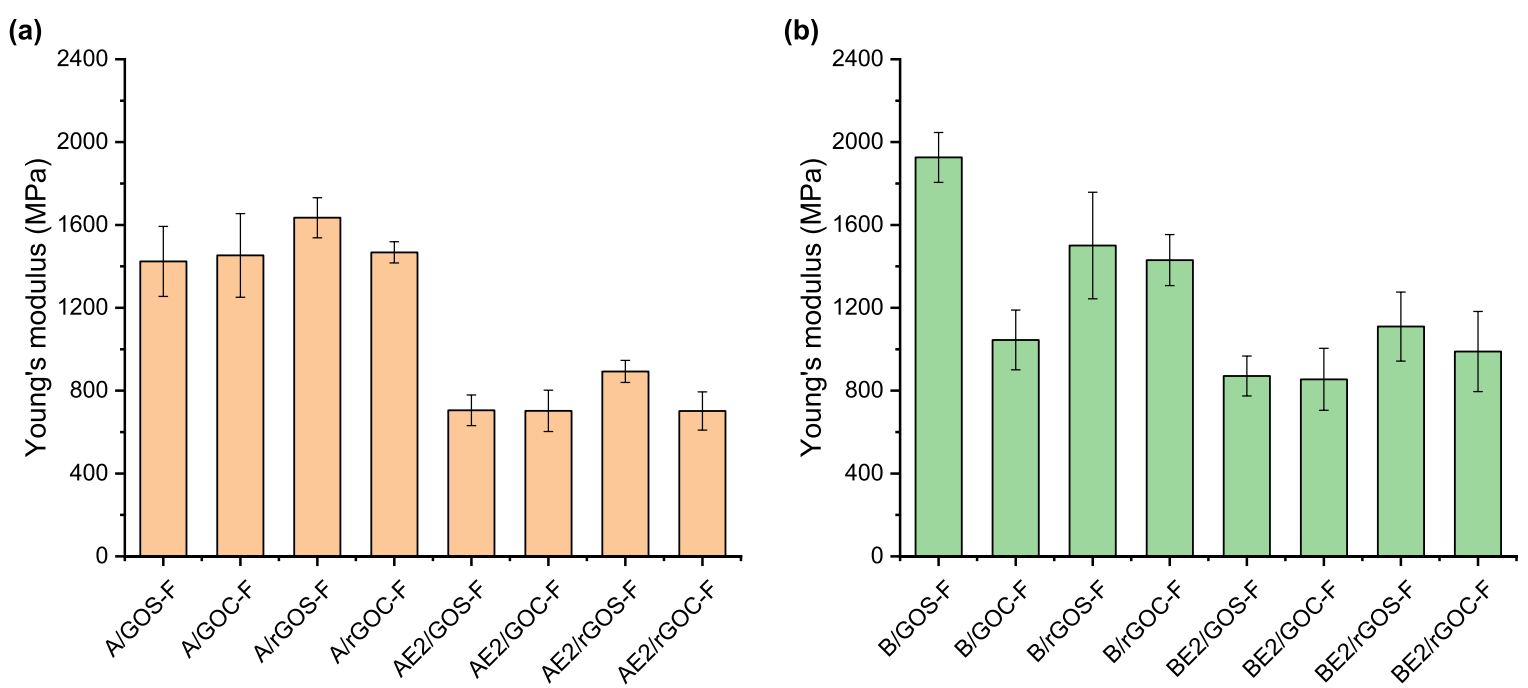

(c)

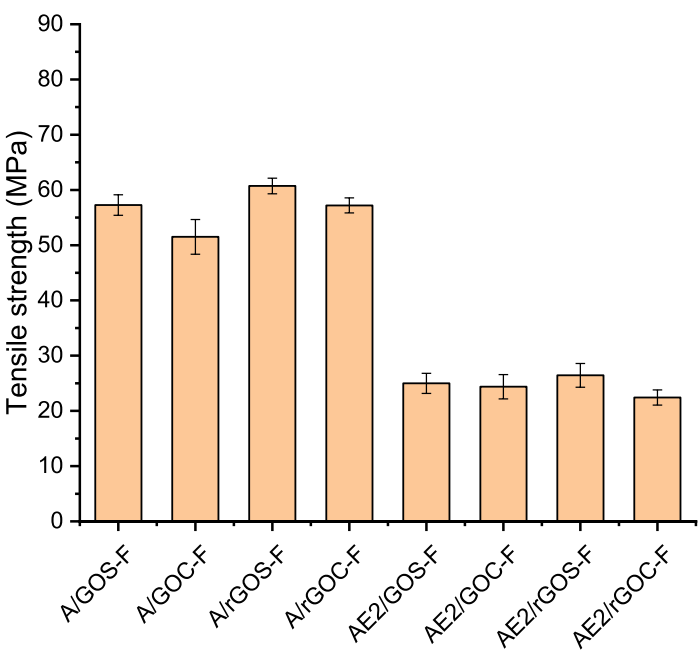

(d)

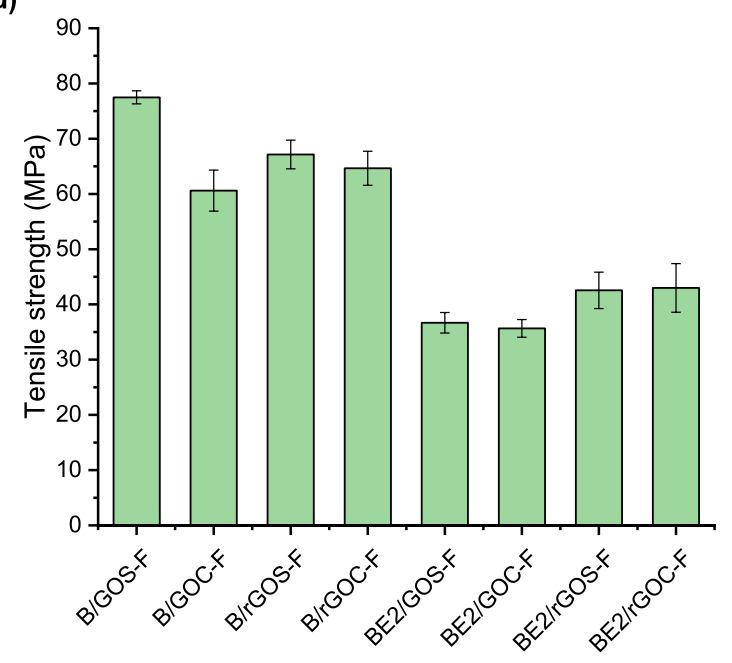

(e)

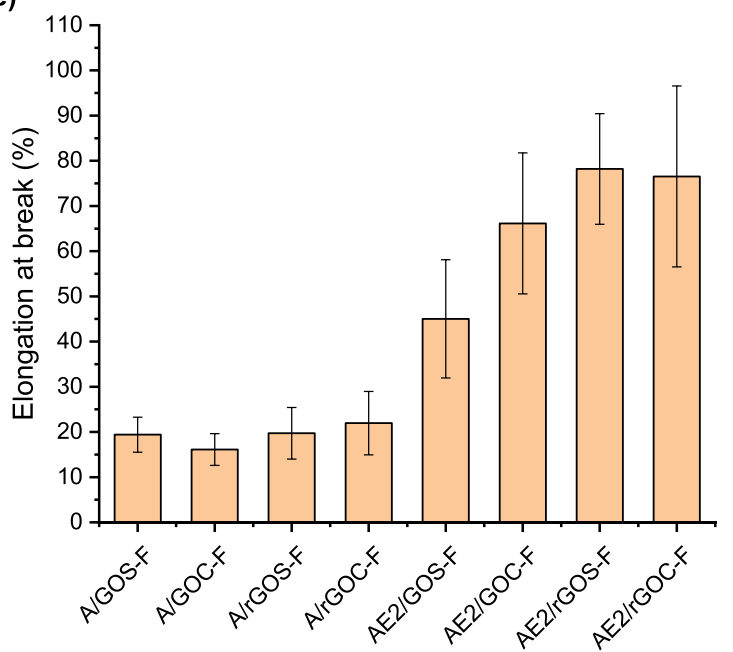

(f)

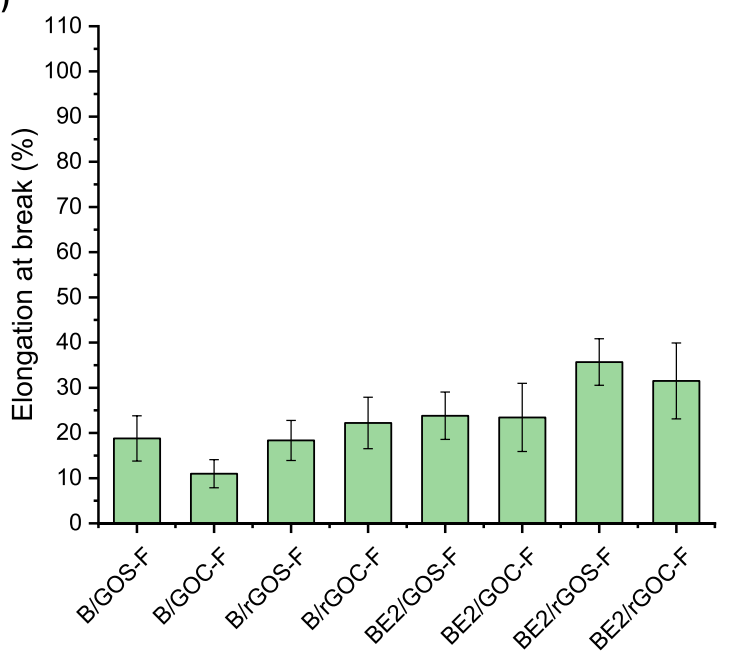

Fig. 6 Tensile mechanical properties (a and $\mathbf{b}$, tensile strength; $\mathbf{c}$ and $\mathbf{d}$, Young's modulus; $\mathbf{e}$ and $\mathbf{f}$, elongation at break) of the different chitosan and chitosan/carboxymethyl cellulose (CMC)-based nanocomposite films. Error bars indicate standard deviations 
(a)

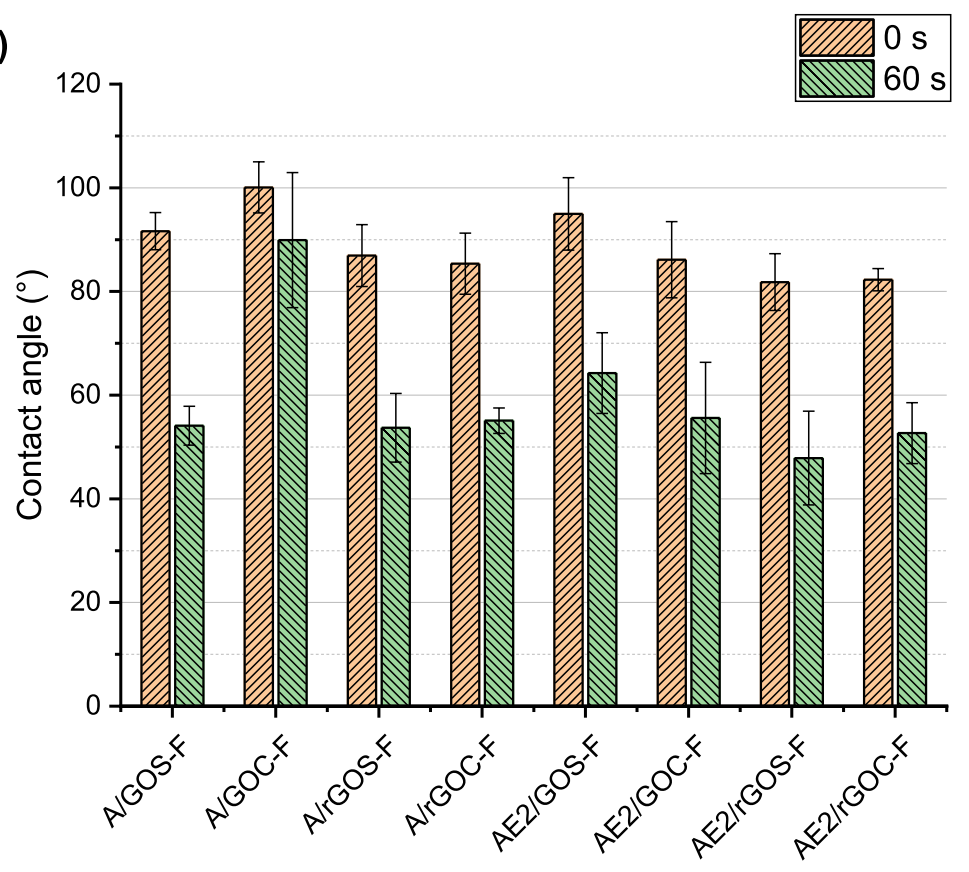

(b)

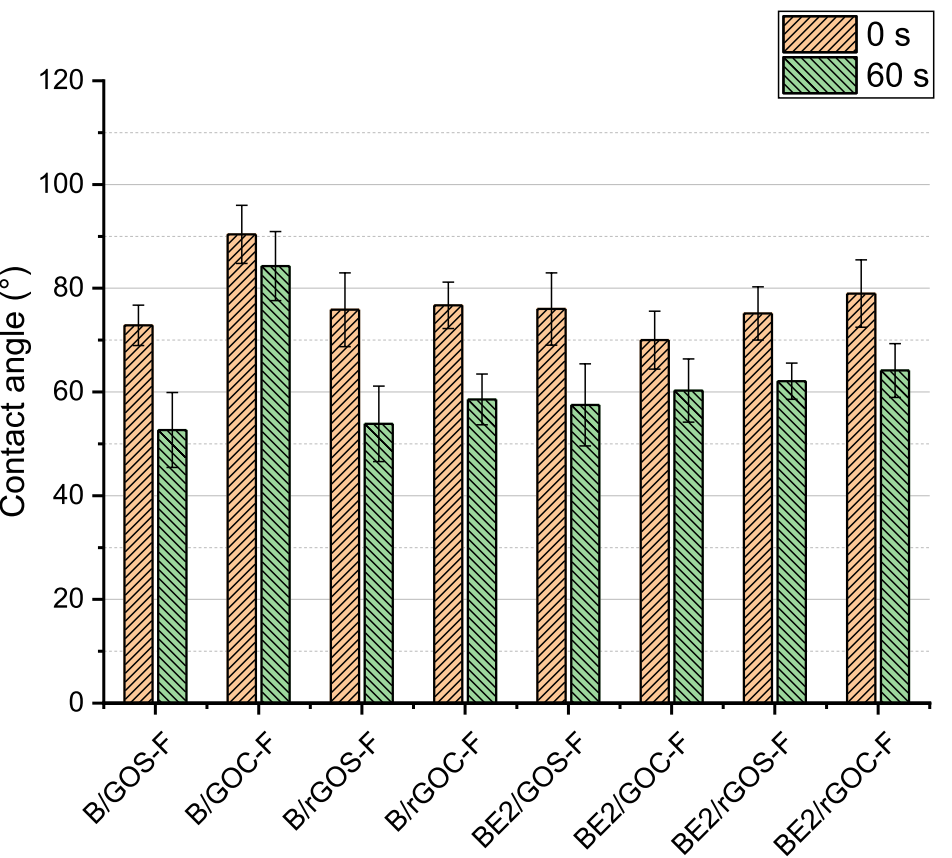

Fig. 7 Contact angle values at $0 \mathrm{~s}$ and $60 \mathrm{~s}$ for the different $\mathbf{a}$ chitosan and $\mathbf{b}$ chitosan/carboxymethyl cellulose (CMC)-based nanocomposite films. The error bars indicate standard deviations

$\sigma_{\mathrm{t}}$. However, rGO was more effective than $\mathrm{GO}$ at increasing Shore D hardness, although its interaction with the polysaccharides was much weaker.

Suitable surface wettability (hydrophilicity/hydrophobicity) of materials is demanded for some applications. For example, cell adhesion occurs preferentially on moderately water-wettable polymer surfaces [45]. Besides, high surface hydrophilicity can lead to a hydrated layer on the materials as a high-surfaceenergy barrier to prevent biofouling (protein absorption) [46]. Figure 7 illustrates the contact angle data for the different bionanocomposites. Water in contact 
with a biopolymer surface may destroy existing hydrogen bonds in the material and make more biopolymer polar groups free to bind with water on the material surface, leading to the contact angle decreasing with the time of wetting [47]. Thus, the contact angle values at $0 \mathrm{~s}$ and $60 \mathrm{~s}\left(\theta_{\mathrm{c} 0 \mathrm{~s}}\right.$ and $\left.\theta_{\mathrm{c} 60 \mathrm{~s}}\right)$ were measured. The surface hydrophilicity of A/GOC-F was similar to that of A/GO-F $\left(\theta_{\mathrm{c} 0 \mathrm{~s}}=99 \pm 5^{\circ}\right.$ and $\left.\theta_{\mathrm{c} 60 \mathrm{~s}}=88 \pm 4^{\circ}\right)$ [35] or $\mathrm{A} / \mathrm{C}-\mathrm{F}\left(\theta_{\mathrm{c} 0 \mathrm{~s}}=96 \pm 6^{\circ}\right.$ and $\left.\theta_{\mathrm{c} 60 \mathrm{~s}}=89 \pm 4^{\circ}\right)$ [36]. However, compared with A/GO-F [35] and A/S-F $\left(\theta_{\text {c0s }}=100 \pm 4^{\circ}\right.$ and $\left.\theta_{c 60 s}=92 \pm 5^{\circ}\right)$ [36], A/GOS-F showed increased surface hydrophilicity as indicated by lower contact angles especially $\theta_{\text {c60s }}\left(54 \pm 4^{\circ}\right)$, which is even lower than the $\theta_{\text {c60s }}$ value for A-F $\left(68 \pm 5^{\circ}\right)$ [21], as the inclusion of GO + SPT disrupted chitosan chain interactions exposing more polar groups (hydroxyl and amine) on the film surface. Moreover, A/rGOS-F and A/rGOC$\mathrm{F}$ had similar contact angle values as those for $\mathrm{A} / \mathrm{rGO}$ $\left(\theta_{\mathrm{c} 0 \mathrm{~s}}=84 \pm 8^{\circ}\right.$ and $\left.\theta_{\mathrm{c} 60 \mathrm{~s}}=55 \pm 4^{\circ}\right)$. While rGO disrupted hydrogen bonding between chitosan chains, SPT or CNCs combined with rGO did not result in a reduction of surface hydrophilicity here as when they were used alone [36], probably because rGO nanosheets hindered the interaction of SPT or CNC with chitosan.

AE2/GOS-F had similar surface hydrophilicity to that of AE2/GO-F $\left(\theta_{\mathrm{c} 0 \mathrm{~s}}=96 \pm 7^{\circ}\right.$ and $\left.\theta_{\mathrm{c} 60 \mathrm{~s}}=63 \pm 8^{\circ}\right)$ [39]. Nonetheless, AE2/GOC-F displayed higher surface hydrophilicity than both AE2/GO-F [39] and $\mathrm{AE} 2 / \mathrm{C}-\mathrm{F}\left(\theta_{\mathrm{cos}}=98 \pm 7^{\circ}\right.$ and $\left.\theta_{\mathrm{c} 60 \mathrm{~s}}=71 \pm 7^{\circ}\right)$ [36]. Moreover, AE2/rGOS-F $\left(\theta_{\mathrm{cos}}=82 \pm 5^{\circ}\right.$ and $\left.\theta_{\mathrm{c} 60 \mathrm{~s}}=48 \pm 9^{\circ}\right)$ and AE2/rGOC-F $\quad\left(\theta_{\mathrm{cos}}=82 \pm 2^{\circ}\right.$ and $\left.\theta_{\mathrm{c} 60 \mathrm{~s}}=53 \pm 6^{\circ}\right)$ displayed higher surface hydrophilicity than AE2/ rGO-F $\left(\theta_{\mathrm{c} 0 \mathrm{~s}}=90 \pm 5^{\circ}\right.$ and $\left.\theta_{\mathrm{c} 60 \mathrm{~s}}=66 \pm 6^{\circ}\right)$ [39], AE2/C$\mathrm{F} \quad\left(\theta_{\mathrm{c} 0 \mathrm{~s}}=98 \pm 7^{\circ}\right.$ and $\left.\theta_{\mathrm{c} 60 \mathrm{~s}}=71 \pm 7^{\circ}\right)$, and AE2/S-F $\left(\theta_{\mathrm{c} 0 \mathrm{~s}}=98 \pm 6^{\circ}\right.$ and $\left.\theta_{\mathrm{c} 60 \mathrm{~s}}=64 \pm 7^{\circ}\right)$ [36]. This indicates for the IL-plasticised A-matrix, there is a synergistic effect when a combination of $1 \mathrm{D}$ and $2 \mathrm{D}$ nanofillers are added to the chitosan (i.e. $\mathrm{GO}+\mathrm{CNCs}, \mathrm{rGO}+\mathrm{SPT}$, or $\mathrm{rGO}+\mathrm{CNCs})$ in disrupting the hydrogen bonding between chitosan chains and/or between chitosan and the IL.

Compared with B/GO-F $\quad\left(\theta_{\mathrm{c} 0 \mathrm{~s}}=92 \pm 6^{\circ} \quad\right.$ and $\theta_{\mathrm{c} 60 \mathrm{~s}}=86 \pm 7^{\circ}$ ) [35], B/GOC-F had similar contact angle values whereas $\mathrm{B} / \mathrm{GOS}-\mathrm{F}$ displayed significantly reduced $\theta_{\mathrm{c} 0 \mathrm{~s}}\left(73 \pm 4^{\circ}\right)$ and $\theta_{\mathrm{c} 60 \mathrm{~s}}\left(53 \pm 7^{\circ}\right)$, even lower than those for $\mathrm{B} / \mathrm{S}-\mathrm{F}\left(\theta_{\mathrm{c} 0 \mathrm{~s}}=82 \pm 5^{\circ}\right.$ and $\left.\theta_{\mathrm{c} 60 \mathrm{~s}}=65 \pm 7^{\circ}\right)$. Again, it seems that a combination of GO+SPT may have disrupted polysaccharide chain interactions more effectively, making more hydroxyl and amine groups exposed on the material surface. Compared with $\mathrm{B} / \mathrm{rGO}-\mathrm{F}\left(\theta_{\mathrm{cos}}=92 \pm 6^{\circ}\right.$ and $\left.\theta_{\mathrm{c} 60 \mathrm{~s}}=86 \pm 7^{\circ}\right)$, both $\mathrm{B} / \mathrm{rGOS} \quad\left(\theta_{\mathrm{cos}}=73 \pm 4\right.$ and $\left.\theta_{\mathrm{c} 60 \mathrm{~s}}=53 \pm 7^{\circ}\right)$ and $\mathrm{B} / \mathrm{rGOC} \quad\left(\theta_{\mathrm{c} 0 \mathrm{~s}}=90 \pm 6\right.$ and $\left.\theta_{\mathrm{c} 60 \mathrm{~s}}=84 \pm 7^{\circ}\right)$ showed increased surface hydrophilicity, although our previous study [36] indicated that inclusion of either SPT or CNCs alone into the un-plasticised B-matrix led to increased surface hydrophobicity. In this sense, $\mathrm{rGO}$ combined with either SPT or CNCs results in a greater concentration of free polar groups as the fillers disrupt polymer chain interactions.

$\mathrm{BE} 2 / \mathrm{rGOS}-\mathrm{F} \quad\left(\theta_{\mathrm{c} 0 \mathrm{~s}}=75 \pm 5^{\circ}\right.$ and $\left.\theta_{\mathrm{c} 60 \mathrm{~s}}=62 \pm 3^{\circ}\right)$ and $\mathrm{BE} 2 / \mathrm{rGOC}-\mathrm{F}\left(\theta_{\mathrm{c} 0 \mathrm{~s}}=79 \pm 6^{\circ}\right.$ and $\left.\theta_{\mathrm{c} 60 \mathrm{~s}}=64 \pm 5^{\circ}\right)$ had lower surface hydrophilicity than BE2/rGO-F $\left(\theta_{\mathrm{c} 0 \mathrm{~s}}=70 \pm 7^{\circ}\right.$ and $\left.\theta_{c 60 \mathrm{~s}}=45 \pm 6^{\circ}\right)$ [39], and they even had higher $\theta_{\mathrm{cos}}$ values than those for BE2/S-F $\left(68 \pm 4^{\circ}\right)$ and BE2/C-F $\left(70 \pm 3^{\circ}\right)$ [36]. In this regard, while SPT and CNCs can interact with the IL or polysaccharides to reduce the availability of polar groups on the composite film surface, their effect was enhanced with the presence of $\mathrm{rGO}$ as a hydrophobic nanofiller.

\section{Conclusions}

This work has shown the possibility for synergistic behaviour when GO or rGO (2D nanofiller) is combined with SPT or CNCs (1D nanofiller), on the structure and properties of polysaccharides (chitosan and $\mathrm{CMC}$ ). Such synergistic behaviour is determined by both filler surface chemistry and the polarity of different biopolymers. Examination of the morphology of these composites using STEM and FTIR data indicate strong interaction between GO and SPT, leading to greater nanoparticle dispersion and the formation of a 3D interconnected microstructure but, reduced interaction between these nanofillers and the polysaccharides. However, for the un-plasticised B-matrix, $\mathrm{GO}+\mathrm{SPT}$ interacted synergistically resulting in an increase in the mechanical properties of the matrix. In contrast, rGO, which is hydrophobic, interacted weakly with SPT and CNCs. For the un-plasticised matrices, the rGO nanosheets were generally found to hinder the interaction of SPT or CNCs with the polysaccharides and, thus, the material properties were mainly determined by rGO. However, for the IL-plasticised A-matrix, it seems addition of a combination of $\mathrm{rGO}+\mathrm{CNCs}$ or $\mathrm{rGO}+\mathrm{SPT}$ was more effective than the nanofiller when used alone at disrupting chitosan chain interactions, resulting in a more plasticised material, increased ductility and surface hydrophilicity. For the IL-plasticised B-matrix, addition of $\mathrm{rGO}+\mathrm{CNCs}$ or $\mathrm{rGO}+\mathrm{SPT}$ resulted in greater thermal stability and increased surface hydrophobicity, possibly by negating the effect of the IL. This study has revealed some interesting effects resulting from the inclusion of $2 \mathrm{D} \mathrm{GO} /$ rGO when combined with 1D CNCs or SPT in chitosan and chitosan/CMC matrices where clearly multiple 
factors (e.g. filler geometry, filler surface chemistry, and polymer-filler interactions) determine material structure and properties.

Thus, the knowledge obtained from this work can guide our future work in designing biopolymer composites with tailored properties (e.g. mechanical properties and surface hydrophilicity) for biomedical (for e.g. wound healing and tissue engineering), biotechnology (as in e.g. cell growth support), fire retardancy, and other high-value applications.

\section{Abbreviations \\ CMC: Carboxymethyl cellulose; IL: Ionic liquid; [ $\mathrm{C}_{2}$ mim] [OAc]: 1-Ethyl-3-methyl- imidazolium acetate; GO: Graphene oxide; rGO: Reduced graphene oxide; SPT: Sepiolite; CNC: Cellulose nanocrystal; $T_{d}$ : Thermal decomposition temperature at the maximum weight decrease rate; $T_{\alpha}$ : Peak temperature of a-transition; $T_{\beta}$ : Peak temperature of $\beta$-transition; $\theta_{c 0 s}$ : Contact angle at $0 \mathrm{~s} ; \theta_{\mathrm{c} 60 \mathrm{~s}}$ : Contact angle at $60 \mathrm{~s}$.}

\section{Supplementary Information}

The online version contains supplementary material available at https://doi. org/10.1186/s42252-021-00026-0.

Additional file 1: Figure S1. Scanning electron microscopy (SEM) images of cryo-fractured surfaces of the different chitosan and chitosan/ CMC-based nanocomposite films. Figure S2. Representative stress-strain curves under tensile testing for the different chitosan and chitosan/CMCbased nanocomposite films. Figure S3. Shore D hardness values of the different chitosan and chitosan/CMC-based nanocomposite films.

\section{Acknowledgements}

P. Chen acknowledges the financial support from the China Scholarship Council (CSC) for her visiting position and thanks IINM, WMG, University of Warwick, UK for hosting her research visit.

\section{Authors' contributions}

Pei Chen: Methodology, Validation, Formal Analysis, Investigation. Fengwei Xie: Conceptualization, Methodology, Validation, Formal analysis, Investigation, Resources, Data Curation, Writing — Original Draft, Writing—Review \& Editing, Visualization, Supervision, Project administration, Funding acquisition. Fengzai Tang: Investigation, Writing—Original Draft. Tony McNally: Conceptualization, Resources, Writing—Review \& Editing, Supervision, Funding acquisition. The author(s) read and approved the final manuscript.

\section{Authors' information}

Pei Chen is an Associate Professor at South China Agricultural University. Her research focuses on the processing and modification of biomass and agricultural products for materials and food applications. She was a visiting scholar at WMG, the University of Warwick, UK from 2018 to 2019.

Fengwei Xie is currently an EPSRC Fellow at WMG, the University of Warwick, UK. His research focuses on 'green'/bio-polymers for materials and food applications. He investigates the mechanisms behind the relationship among processing, structure and properties/functionality of biopolymers and biocomposites.

Fengzai Tang completed his PhD degree at the University of Sydney, Australia in 2008. He currently works at WMG, the University of Warwick, UK as an Engineer in microscopy and nanoanalysis.

Tony McNally is Chair Professor in Nanocomposites and founder and, first Director of the International Institute for Nanocomposites Manufacturing (IINM) at WMG, the University of Warwick, UK. His research interests include composites of $0 \mathrm{D} / 1 \mathrm{D} / 2 \mathrm{D}$ nanomaterials and polymers, functionalization of nanomaterials, processing-structure-property relationships in polymer science, compatibilisation of immiscible polymer blends, mechanochemistry, and polymer modified bitumen.

\section{Funding}

This project has received funding from the European Union's Horizon 2020 research and innovation programme under the Marie Skłodowska-Curie grant agreement No. 798225.

\section{Availability of data and materials}

The datasets used and/or analysed during the current study are available from the corresponding author on reasonable request.

\section{Declarations}

\section{Competing interest}

The authors declare that they have no competing interests.

\section{Author details}

${ }^{1}$ College of Food Science, South China Agricultural University, Guangzhou 510642, China. ${ }^{2}$ International Institute for Nanocomposites Manufacturing (IINM), WMG, University of Warwick, Coventry CV4 7AL, UK. ${ }^{3}$ WMG, University of Warwick, Coventry CV4 7AL, UK.

Received: 2 March 2021 Accepted: 8 September 2021

Published online: 26 September 2021

\section{References}

1. M. Rinaudo, Prog. Polym. Sci. 31, 603 (2006)

2. M.N.V. Ravi Kumar, Reactive Funct. Polym. 46, 1 (2000)

3. M.Z. Elsabee, E.S. Abdou, Mater. Sci. Eng. C 33, 1819 (2013)

4. A. Muxika, A. Etxabide, J. Uranga, P. Guerrero, K. de la Caba, Int. J. Biol. Macromol. 105, 1358 (2017)

5. V.K. Mourya, N.N. Inamdar, React. Funct. Polym. 68, 1013 (2008)

6. S. Wang, A. Lu, L. Zhang, Prog. Polym. Sci. 53, 169 (2016)

7. H.P.S. Abdul Khalil et al., Carbohydr. Polym. 150, 216 (2016)

8. Y.-B. Wu, S.-H. Yu, F.-L. Mi, C.-W. Wu, S.-S. Shyu, C.-K. Peng, A.-C. Chao, Carbohydr. Polym. 57, 435 (2004)

9. C. Stefanescu, W.H. Daly, I.I. Negulescu, Carbohydr. Polym. 87, 435 (2012)

10. C. Rosca, M.I. Popa, G. Lisa, G.C. Chitanu, Carbohydr. Polym. 62, 35 (2005)

11. A.M. Youssef, S.M. El-Sayed, H.S. El-Sayed, H.H. Salama, A. Dufresne, Carbohydr. Polym. 151, 9 (2016)

12. D. Hu, H. Wang, L. Wang, LWT Food Sci. Technol. 65, 398 (2016)

13. N. Noshirvani, B. Ghanbarzadeh, C. Gardrat, M.R. Rezaei, M. Hashemi, C. Le Coz, V. Coma, Food Hydrocolloids 70, 36 (2017)

14. L. Jiang, Y. Li, X. Wang, L. Zhang, J. Wen, M. Gong, Carbohydr. Polym. 74, $680(2008)$

15. J. Liuyun, L. Yubao, X. Chengdong, J. Biomed. Sci. 16, 65 (2009)

16. R. Sainitya, M. Sriram, V. Kalyanaraman, S. Dhivya, S. Saravanan, M. Vairamani, T.P. Sastry, N. Selvamurugan, Int. J. Biol. Macromol. 80, 481 (2015)

17. N.-Y. Yuan, Y.-A. Lin, M.-H. Ho, D.-M. Wang, J.-Y. Lai, H.-J. Hsieh, Carbohydr. Polym. 78, 349 (2009)

18. S. Basu, A. Plucinski, J.M. Catchmark, Green Chem. 19, 4080 (2017)

19. N. Dhar, S.P. Akhlaghi, K.C. Tam, Carbohydr. Polym. 87, 101 (2012)

20. T. Mitsumata, Y. Suemitsu, K. Fujii, T. Fujii, T. Taniguchi, K. Koyama, Polymer 44, 7103 (2003)

21. P. Chen, F. Xie, F. Tang, T. McNally, Compos. Sci. Technol. 189, 108031 (2020)

22. J. Shang, Z. Shao, X. Chen, Biomacromol 9, 1208 (2008)

23. J. Duan, X. Liang, K. Zhu, J. Guo, L. Zhang, Soft Matter 13, 345 (2017)

24. R. Xiong, A.M. Grant, R. Ma, S. Zhang, V.V. Tsukruk, Mater. Sci. Eng. R 125, 1 (2018)

25. T. Kuilla, S. Bhadra, D. Yao, N.H. Kim, S. Bose, J.H. Lee, Prog. Polym. Sci. 35, 1350 (2010)

26. J. Chen, H. Peng, X. Wang, F. Shao, Z. Yuan, H. Han, Nanoscale 6, 1879 (2014) 
27. F. Perreault, A.F. de Faria, S. Nejati, M. Elimelech, ACS Nano 9, 7226 (2015)

28. M. Di Giulio, R. Zappacosta, S. Di Lodovico, E. Di Campli, G. Siani, A. Fontana, L. Cellini, Antimicrob. Agents Chemother. 62, e00547 (2018)

29. A. Al-Jumaili, S. Alancherry, K. Bazaka, M.V. Jacob, Materials 10, 1066 (2017)

30. X. Yang, Y. Tu, L. Li, S. Shang, X.-M. Tao, A.C.S. Appl, Mater. Interfaces 2, 1707 (2010)

31. F. Chivrac, E. Pollet, M. Schmutz, L. Avérous, Biomacromol 9, 896 (2008)

32. F. Chivrac, E. Pollet, M. Schmutz, L. Avérous, Carbohydr. Polym. 80, 145 (2010)

33. T. Abitbol, D. Kam, Y. Levi-Kalisman, D.G. Gray, O. Shoseyov, Langmuir $\mathbf{3 4}$ 3925 (2018)

34. H. Wang, M. Roman, Biomacromol 12, 1585 (2011)

35. P. Chen, F. Xie, F. Tang, T. McNally, Int. J. Biol. Macromol. 158, 420 (2020)

36. P. Chen, F. Xie, F. Tang, T. McNally, Polymers 13, 571 (2021)

37. N. El Miri, M. El Achaby, A. Fihri, M. Larzek, M. Zahouily, K. Abdelouahdi, A. Barakat, A. Solhy, Carbohydr. Polym. 137, 239 (2016)

38. P. Chen, F. Xie, F. Tang, T. McNally, Nanocomposites 6, 125 (2020)

39. P. Chen, F. Xie, F. Tang, T. McNally, ACS Omega 5, 19070 (2020)
40. G. Lawrie, I. Keen, B. Drew, A. Chandler-Temple, L. Rintoul, P. Fredericks, L. Grøndahl, Biomacromol. 8, 2533 (2007)

41. A. Pawlak, M. Mucha, Thermochim. Acta 396, 153 (2003)

42. Z. Chen, X. Mo, C. He, H. Wang, Carbohydr. Polym. 72, 410 (2008)

43. I. Quijada-Garrido, B. Laterza, J.M. Mazón-Arechederra, J.M. BarralesRienda, Macromol. Chem. Phys. 207, 1742 (2006)

44. I. Quijada-Garrido, V. Iglesias-González, J.M. Mazón-Arechederra, J.M. Barrales-Rienda, Carbohydr. Polym. 68, 173 (2007)

45. P.B. van Wachem, T. Beugeling, J. Feijen, A. Bantjes, J.P. Detmers, W.G. van Aken, Biomaterials 6, 403 (1985)

46. T. Mohan, R. Kargl, K.E. Tradt, M.R. Kulterer, M. Braćić, S. Hribernik, K. StanaKleinschek, V. Ribitsch, Carbohydr. Polym. 116, 149 (2015)

47. P. Chen, F. Xie, F. Tang, T. McNally, Eur. Polym. J. 144, 110225 (2021)

\section{Publisher's Note}

Springer Nature remains neutral with regard to jurisdictional claims in published maps and institutional affiliations.

\section{Submit your manuscript to a SpringerOpen ${ }^{\circ}$ journal and benefit from:}

- Convenient online submission

- Rigorous peer review

- Open access: articles freely available online

- High visibility within the field

- Retaining the copyright to your article

Submit your next manuscript at $\boldsymbol{\nabla}$ springeropen.com 